\title{
3D Integrated Numerical Model for Fluid-Structures-Seabed Interaction (FSSI): Loosely Deposited Seabed Foundation
}

\author{
Ye Jianhong ${ }^{a, b}$ Jeng D-S ${ }^{c}$ Chan A H $\mathrm{C}^{d}$ Wang $\mathrm{R}^{a}$ Zhu Q $\mathrm{C}^{a}$ \\ a State Key Laboratory of Geomechanics and Geotechnical Engineering, Institute of Rock and Soil Mechanics, \\ Chinese Academy of Sciences, Wuhan 430071 China \\ b Division of Civil Engineering, University of Dundee, Dundee, DD1 4HN UK \\ c Griffith School of Engineering, Griffith University, Gold Coast, Queensland 4222, Australia \\ d School of Information and Communication Technology, University of Tasmania, Hobart, Austrilia \\ Corresponding to yejianhongcas@gmail.com
}

August 18, 2016

\begin{abstract}
In the past several decades, a great number of offshore structures have been constructed on loosely deposited seabed foundation because sometimes there would be no a dense seabed floor could be chosen in planned sites, for example, the breakwaters and oil platforms in the Yellow River estunary area, China. Wave-induced residual liquefaction is easy to occur in loosely deposited seabed, which brings great risk to the stability of offshore structures. In this study, we focus our attention on the 3D interaction mechanism between ocean wave, a caisson breakwater and its loosely deposited seabed foundation. A three-dimensional integrated numerical model FSSI-CAS 3D is taken as the computational tool; and the soil constitutive model: Pastor-Zienkiewicz Mark III (PZIII) proposed by Pastor et al. (1990) is adopted to describe the wave-induced dynamic behavior of loose seabed soil. The numerical results indicate that the developed integrated numerical model FSSI-CAS 3D is capable of capturing a series of nonlinear phenomena, such as tilting, subsiding of breakwater, as well as residual liquefaction in loose seabed foundation etc., in the interaction process between ocean wave, a caisson breakwater and its loose seabed foundation. The purpose of this study is to provide coastal engineers with comprehensive understanding of FSSI problme involving loosely deposited seabed soil; and propose a reliable computational method to engineers involved in the design of offshore structures on loose seabed foundation.
\end{abstract}

Keywords: Fluid-Structures-Seabed Interaction (FSSI); Loosely deposited seabed foundation; 3D residual liquefaction; Caisson breakwater; PZIII; FSSI-CAS 3D

\section{Introduction}

There are a great deal of newly deposited Quaternary loose sediment in offshore area in the world, for example, the Yellow River estunary area in China. An important characteristics of these offshore Quaternary sediment is that soil particles are relatively loose; and their relative density $D_{r}$ is small. As a result, these Quaternary 
offshore soils has low P wave speed, and low SPT (Standard Penetration Test) value; and their bearing capacity is also weak. From the perspective of engineering practice, offshore Quaternary sediment is not an ideal choice as the foundation of offshore structures. The main reason can be attributed to the fact that Quaternary loose sediments are easy to liquefy under ocean wave or seismic wave loading. It is well known that a liquefied seabed soil behaves like a kind of heavy fluid; it can not support any overlying strucuture. As a result, offshore structures built on Quaternary loose sediment are more suspectable to lost stability during their usage lifetime under ocean/seismic wave loading. Sometimes, coastal engineers have to face the situation that there is no other choice in a planned site. Under the situation that a Quaternary sediment seabed has to be chosen as the foundation of designed offshore structures, evaluation of the stability of designed offshore structures under ocean/seismic wave is apparently necessary. This stability evaluation for offshore structures must be based on comprehensive investigation of the complicated interaction between ocean wave, offshore structures and their loose seabed foundation. In the engineering of practice, it is desirable that if there is a reliable numerical model available for this purpose.

Currently, there are some investigations on the topic of wave-induced dynamics of elasto-plastic sand soil, and related marine structures available. The investigation methods include decoupled analytical solution (Rahman and Jaber, 1986; Cheng et al., 2001; Sumer et al., 2011), decoupled numerical modelling (Li and Jeng, 2008; Dunn et al., 2006; Sassa and Sekiguchi, 2001; Sassa et al., 2001), as well as laboratory test (Sassa and Sekiguchi, 1999; Kirca et al., 2013; Zhang et al., 2009; Groot et al., 2006; Kudella et al., 2006). In these analytical solutions, a source term function was added to pore pressure dissipation equation to approximately describe the mechanism of pore pressure build-up. Actually, the simplified source term function based on constant magnitude of wave-induced shear stress is unlikely to describe the mechanism accurately, for example, it generally assumes that the magnitude of wave-induced shear stress in loose seabed soil was constant. This assumption is obviously unreasonable because the shear stress will gradually reduce to zero in the liquefaction process (Ye and Wang, 2015, 2016). As a result, the predicted pore pressure is not reliable. They can not agree with experimental data in most cases. Additionally, analytical solutions can not handle complex boundary conditions and soil constitutive models; and the variation of effective stress also can not be determined in computation. Numerical models have the natural advantages to handle complex boundary conditions and soil constitutive models. However, linear or nonlinear Stokes wave was utilized to apply wave loading on seabed floor in previous literature. The fluid-structures interaction, and the fluid exchange between sea water and pore water in loose seabed also were not taken into consideration. As an integrated system between ocean wave, offshore structures and their loose seabed foundation, a coupled numerical model should be used to investigate 


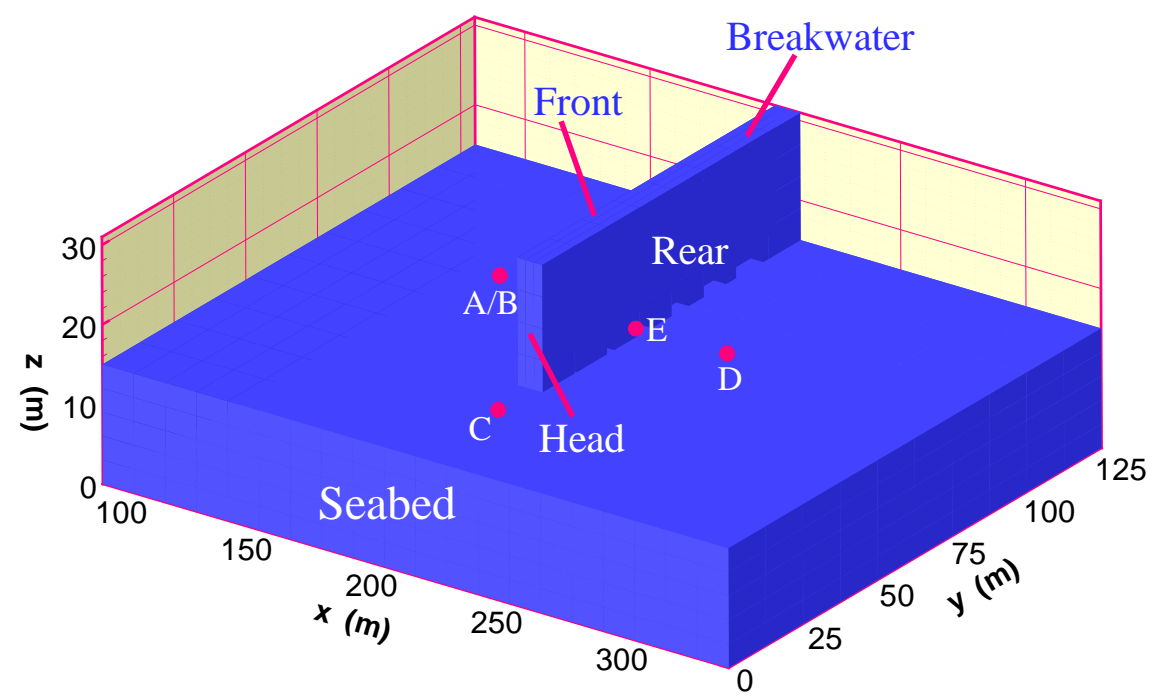

Figure 1: Configuration of chosen computational domain. A caisson breakwater (Length $\times$ Width $\times$ Height $=90 \mathrm{~m} \times 10 \mathrm{~m} \times 16 \mathrm{~m})$ is constructed on a loose seabed foundation. The dimension of seabed is Length $\times$ Width $\times$ Height $=250 \mathrm{~m}(x=80 \mathrm{~m}-330 \mathrm{~m}) \times 130 \mathrm{~m} \times 15 \mathrm{~m}$. The position of the caisson breakwater is $x=200-210 \mathrm{~m}$, $y=40-130 \mathrm{~m}, z=15-31 \mathrm{~m}$. Five typical positions labelled as A, B, C, D, E around the breakwater head are chosen in results analysis. Their projection on plane $z=15 \mathrm{~m}$ are shown

their interaction. Ye et al. (2013b) developed a semi-coupled numerical model FSSI-CAS 2D for this purpose; and this model has been validated by a wave flume test (Teh et al., 2003) and a centrifuge test (Sassa and Sekiguchi, 1999). Based on the fact that most previous numerical models for FSSI problem are limited to 2D, Ye et al. (2013a) further extended 2D package to form FSSI-CAS 3D. At present, FSSI-CAS 3D is capable of investigating the complicated interaction between ocean wave, offshore structures and their loose seabed foundation.

In this study, the configuration of breakwater and its seabed foundation is shown in Figure 1. As shown in Figure 1, a caisson breakwater is constructed on a loosely deposited seabed foundation. The wave-induced dynamics of the loose seabed foundation around the caisson breakwater is investigated in an integrated way, by adopting FSSI-CAS 3D. The wave-induced pore pressure build up, variation of effective stresses, and residual liquefaction potential in loose seabed foundation are the focus of this study. The purpose is to provide engineers with comprehensive understanding of FSSI problem involving loosely deposited seabed foundation; and propose a reliable computational method to coastal engineers involved in the design of offshore structures on loose seabed. 


\section{Integrated numerical model and constitutive model}

The integrated numerical model FSSI-CAS 3D for fluid-seabed-structures interaction contains two modules: wave model and soil model. The wave model is responsible for the generation, propagation of wave, and determines the pressure acting on seabed and marine structures in computation. The modified Navier-Stokes equations are the governing equation for wave motion on seabed, and its interaction with marine structures, as well as porous flow in loose seabed. They are solved by using a FVM-based N-S solver provided by the open source code TRUCHAS (2009) developed by US Los Alamos National Laboratory (LANL). In TRUCHAS, VOF method is adopted to trace the free surface of wave motion. The drag force between pore fluid and

solid matrix is formulated as $F_{d i}=C_{d} \frac{v}{d_{50}^{2}} \frac{(1-n)^{2}}{n^{2}} u_{f i}$ (Hur et al., 2010). In this wave model, the internal wave maker proposed by Lin and Liu (1999) is applied to generate the target wave train, in which a mass function is added to the continuity equation at the position where the wave maker is located. The soil model determines the dynamic response of seabed and marine structures taking the wave-induced pressure/force on seabed and marine structures determined by wave model as the boundary value. The dynamic Biot's equation known as 'u-p' approximation is the governing equation for dynamics of soil and structures. It is solved adopting a FEM-based solver, in which Generalized Newmark- $\beta$ method is used for time integration, and NewtonRaphson method is used for global iteration.

In this integrated numerical model, the non-match mesh scheme and non-match time step are used in coupling computation. A data exchange port is developed adopting 3D Shepard interpolation method to transmit data at the interface between fluid domain and solid domain. In the integrated model, pressure and flux continuity on interfaces between fluid domain and solid domain is applied all the time in computation. More information about the integrated model FSSI-CAS 3D can be found in Ye et al. (2013b).

It seems to be that a monolithical scheme (Blom, 1998) is used in computation. There is no feedback from solid domain to fluid domain. Actually, the coupling between the wave model and soil model can be referred to as a semi-coupling process (Ye et al., 2013b), because the seabed foundation is considered as porous medium in wave model when determining wave field; the effect of porosity of seabed foundation on wave field has been taken into consideration. Therefore, the flow field in fluid domain and solid domain is continuous at their interfaces. However, the displacement at interfaces is not continuous. From the point view of physics, the wave-induced vibration of marine structures and seabed foundation generally is apparently minor comparing with the wave length. The discontinuity of displacement between fluid domain and solid domain is acceptable if there is no large deformation involved. If displacement continuity on interfaces must be implemented through iterative process (also referred as to staggered scheme (Farhat and Lesoinne, 2000)), 
the computation will be very expensive. Additionally, as far as we know, there is no a code so far can implement the fully coupled computation for fluid-seabed-structures interaction problem.

The developed 3D integrated numerical model FSSI-CAS 3D has been validated by an analytical solution (Hsu and Jeng, 1994) and a laboratory wave flume tests (Mizutani et al., 1998) for the problem of ocean wavemarine structure-dense seabed foundation interaction (Ye et al., 2013a). The verification of FSSI-CAS 2D for the problem of ocean wave-loose seabed interaction also has been conducted in Ye et al. (2013b). Due to the fact that FSSI-CAS 3D is developed under the same frame of FSSI-CAS 2D, it is certainly sure that FSSI-CAS 3D is applicable for the problem of wave-loose seabed-marine structures interaction.

Quaternary newly deposited loose sediments widely exist in offshore area. Under cyclic loading, soil compaction due to uncoverable plastic volumetric deformation would occur in loose sediments. In this study, an advanced elasto-plastic constitutive model: Pastor-Zienkiewicz Mark III (PZIII) proposed by Pastor et al. (1990) is adopted to describe the wave-induced dynamic behavior of loose seabed soil. PZIII is an excellent constitutive model to describe the behaviors of clay and sandy soil. Its reliability has been validated by a series of laboratory tests involving monotonic and cyclic loading (Zienkiewicz et al., 1999), especially in the project VELACS. This model is one of the heritage of Olek Zienkiewicz (Pastor et al., 2011). More information about PZIII model can be found in Pastor et al. (1990) and (Zienkiewicz et al., 1999). Previous investigation conducted by Ye et al. (2015) has evidently proved that PZIII model is capable of modelling the wave-induced dynamics of loose seabed foundation. A series of physical mechanism of loose soil to cyclic loading revealed by experimental tests can be effectively captured by PZIII model.

\section{Boundary condition applied}

In computation, the bottom of loose seabed foundation is fixed; and the lateral sides are only fixed in horizontal direction. On the surface of seabed, the wave-induced pressure and hydrostatic pressure are applied instantaneously. At the meantime, the pore pressure in seabed foundation and the water pressure in seawater are continuous on the surface of seabed, guaranteeing the effective stresses on seabed surface is zero all the time. The caisson breakwater is applied by the wave-induced pressure and hydrostatic pressure on its lateral sides; and its bottom is applied by upward bouyant. The caisson breakwater is treated as a rigid body with aparent small permeability. 


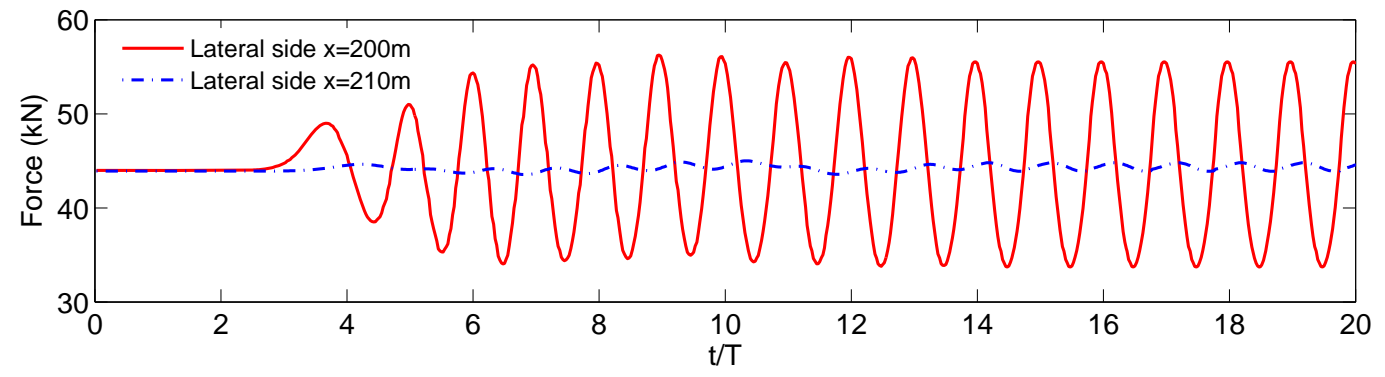

Figure 2: Wave-induced force on the front and rear lateral sides of the caisson breakwater

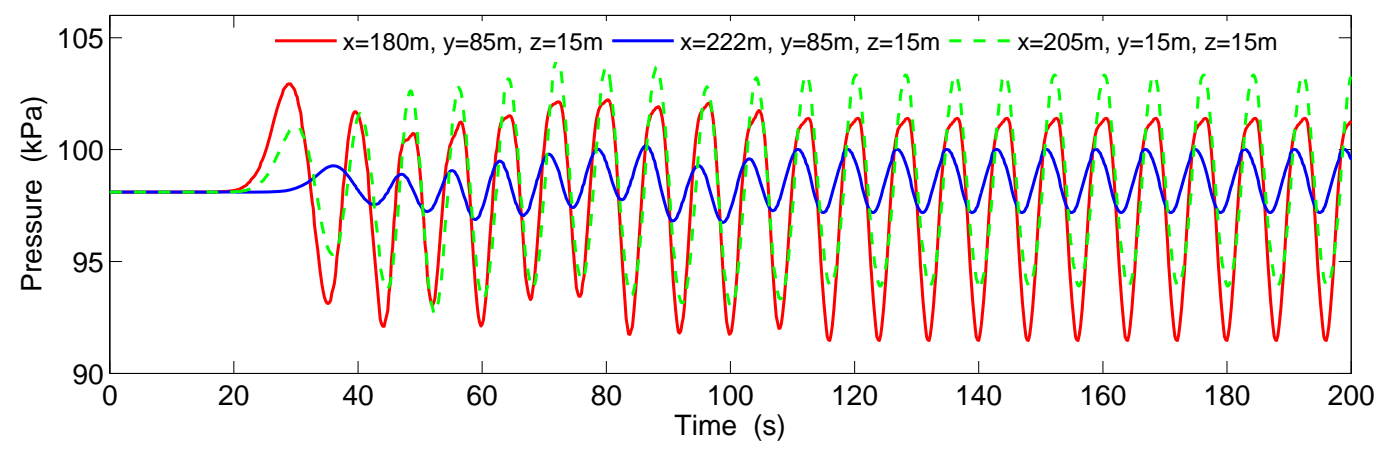

Figure 3: Wave-induced dynamic pressure acting on the seabed foundation around the head of caisson breakwater.

\section{Dynamic response of caisson breakwater}

The parameters of wave characteristics for wave maker here are: $H=1.5 \mathrm{~m}, d=10.0 \mathrm{~m}$, and $T=8.0 \mathrm{~s}$. In CFD computation, a series of absorption zones are set to absorb the wave energy on boundaries, avoiding the unexpected wave reflection. The property parameters of seabed soil for PZIII model in computation are listed in Table 1. They were determined by Zienkiewicz et al. (1999) from the laboratory tests of Nevada sand in the VELACS project funded by American National Science Foundation (NSF). Here, the parameters from Nevada sand just is an example in this numerical simulation. For a real seabed soil, engineers must conduct laboratory tests on soils sampled from seabed foundation, to determine the mechanical parameters for PZIII model or other constitutive models.

Taking the consolidation state of the seabed foundation under the caisson breakwater and hydrostatic pressure determined as that in Ye et al. (2012), as the initial condition, wave-induced dynamics of the caisson breakwater, and its loosely deposited seabed foundation is investigated in the followings. In this study, it is stipulated that compression is taken as negative value; and displacement is taken as positive value if it is in $+x$, $+y,+z$ direction. 
Table 1: Properties and parameters used for seabed foundation, composite breakwater and wave in analysis and parametric study

\begin{tabular}{lcc}
\hline \hline \multicolumn{3}{c}{ Parameters for PZ3 model (from Nevada sand) } \\
\hline Iterm & Value & Unit \\
$K_{\text {evo }}$ & 2,000 & {$[\mathrm{kPa}]$} \\
$G_{\text {eso }}$ & 2,600 & {$[\mathrm{kPa}]$} \\
$p_{0}^{\prime}$ & 4 & {$[\mathrm{kPa}]$} \\
$M_{g}$ & 1.32 & - \\
$M_{f}$ & 1.3 & - \\
$\alpha_{f}$ & 0.45 & - \\
$\alpha_{g}$ & 0.45 & - \\
$\beta_{0}$ & 4.2 & - \\
$\beta_{1}$ & 0.2 & - \\
$H_{0}$ & 750 & - \\
$H_{U 0}$ & 40,000 & {$[\mathrm{kPa}]$} \\
$\gamma_{u}$ & 2.0 & - \\
$\gamma_{D M}$ & 4.0 & - \\
\hline \hline Soil characteristics & & \\
\hline Soil permeability $(k)$ & $1.0 \times 10^{-5}$ & {$[\mathrm{~m} / \mathrm{s}]$} \\
Poisson's ratio $(v)$ & 0.3333 & \\
Saturation $\left(S_{r}\right)$ & 95,98 or 100 & $\%$ \\
Porosity $(n)$ & 0.25 & \\
Relative density $\left(D_{r}\right)$ & $60 \%$ & \\
\hline \hline Breakwater & & \\
\hline Permeability $(k)$ & $1.0 \times 10^{-10}$ & {$[\mathrm{~m} / \mathrm{s}]$} \\
Poisson's ratio $(v)$ & 0.25 & \\
Saturation $\left(S_{r}\right)$ & 0 & \\
Young's modulus $(E)$ & $1.0 \times 10^{4}$ & {$[\mathrm{MPa}]$} \\
Porosity $(n)$ & 0.1 & \\
\hline \hline Wave characteristics & & \\
\hline Wave height & 1.5 & \\
Wave period & 8.0 & \\
Water depth & 10 & \\
\hline \hline
\end{tabular}



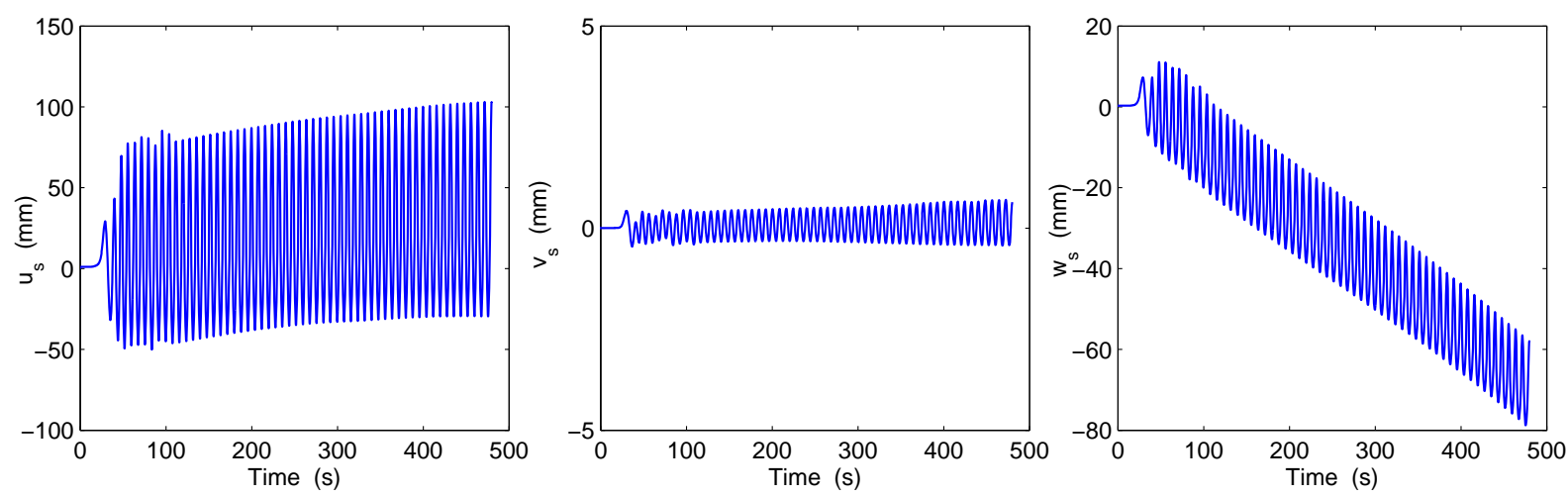

Figure 4: Displacement of caisson breakwater on loosely deposited seabed foundation under wave loading

There are three kinds of wave field around the caisson breakwater: standing wave in front of the caisson breakwater, diffracted wave behind the caisson breakwater, and progressive wave near to the breakwater head. Wave impact on the caisson breakwater applied by designed wave is an important factor need to be considered in design of marine structure. Figure 2 demonstrates the ocean wave-induced force on the front and rear lateral sides of the caisson breakwater. It is clearly seen that the wave-induced force acting on the front lateral side of the caisson breakwater is much greater than that on its rear lateral side. Figure 3 shows the wave-induced dynamic pressure acting on the seabed foundation around the head of caisson breakwater. It is clearly observed that wave-induced dynamic pressure acting on the seabed in front of the breakwater, and near to breakwater head is also much higher than that behind the breakwater. It is indicated that the standing wave in front of the caisson breakwater, and the progressive wave near the breakwater head play a dominant role for the dynamics of the caisson breakwater and its seabed foundation.

Figure 4 illustrates the wave-induced displacements of the caisson breakwater constructed on the loosely deposited seabed foundation. It can be found that the caisson breakwater mainly vibrates to $+x$ and $-x$ direction periodically. The vibration amplitude is about $70 \mathrm{~mm}$. It is indicated that wave-induced dynamic response of breakwater on a loose seabed foundation is much stronger than that on a dense seabed foundation. Additionally, the caisson breakwater has a permanent horizontal displacement toward to $-x$ direction (reach up to $50 \mathrm{~mm}$ ). This is significantly different with that if the caisson breakwater is built on a dense seabed foundation(Ye et al., 2016b), in which there is no residual displacement. Another phenomenon observed in Figure 4 is that the caisson breakwater gradually subsides, which is attributed to soil compaction resulted from the rearrangement of soil particles under cyclic loading. This is a unfavorable factor for the stability of breakwater built on loose seabed foundation. In general, the construction of a marine structure on loosely deposited seabed is much more dangerous than that on dense seabed. 


\section{Dynamic response of seabed foundation}

It has been widely recognized that pore pressure could builds up, and effective stresses reduces in a poro loose seabed foundation resulted from cyclic wave loading. However, how the caisson breakwater affects pore pressure build up, and effective stresses reduction in the region around a breakwater head is not fully understood so far. In this section, the effect of the caisson breakwater on pore pressure and effective stresses in loose seabed foundation is investigated. Five typical positions are chosen as the representatives for the analysis: A $(x=164 \mathrm{~m}, y=85 \mathrm{~m}, z=13 \mathrm{~m})$ in front of the breakwater, $\mathrm{B}(x=164 \mathrm{~m}, y=85 \mathrm{~m}, z=8 \mathrm{~m})$ in front of the breakwater, $\mathrm{C}(x=205 \mathrm{~m}, y=15 \mathrm{~m}, z=13 \mathrm{~m})$ near to the breakwater head, $\mathrm{D}(x=246 \mathrm{~m}, y=85 \mathrm{~m}, z=13 \mathrm{~m})$ behind the breakwater, and $\mathrm{E}(x=205 \mathrm{~m}, y=85 \mathrm{~m}, z=13 \mathrm{~m})$ under the breakwater.

Figure 5, 6, 7 and 8 illustrate the time history of pore pressure build up, and effective stresses reduction at the five chosen positions around the caisson breakwater. In Figure 5 (a), it can be seen that the pore pressure at A does not continuously build up after $t=200 \mathrm{~s}$. The residual pore pressure basically keep $23 \mathrm{kPa}$; and the

magnitude of oscillatory pore pressure is about 10kPa after $t=200 \mathrm{~s}$. Meanwhile, effective stress $\sigma_{x}^{\prime}$ and $\sigma_{z}^{\prime}$ nearly approaches zero from their initial compressive state. Under such situation, it is indicated that the seabed soil at position $\mathrm{A}$ in front of the breakwater becomes liquefied after $t=200 \mathrm{~s}$. In Figure 5 (b), it is found that although the wave-induced residual pore pressure at B reaches up to about $47 \mathrm{kPa}$, much greater than that at A, the effective stresses $\sigma_{x}^{\prime}$ and $\sigma_{z}^{\prime}$ are still far away from the zero stress state (complete liquefaction state). This is attributed to the fact that buried depth of position B is much deeper than that of position A. The initial self-gravity induced effective stresses at position B is much greater than that at position A. It makes the soil at $\mathrm{B}$ is much more difficult to liquefy.

In Figure 6 and 7, it is found that pore pressure in the seabed near at position $\mathrm{C}$ to the breakwater head, and at position $\mathrm{D}$ behind the breakwater continuously builds up in the whole process of wave loading. Correspondingly, effective stresses between soil particles at the two positions continuously reduce. This phenomenon is significantly different with that in front of the caisson breakwater. There is a gap to the zero stress (full liquefaction state) at position $\mathrm{C}$ and $\mathrm{D}$. The difference to zero vertical effective stress is about $2.5 \mathrm{kPa}$ and $20 \mathrm{kPa}$, respectively at the two typical position $\mathrm{C}$ and $\mathrm{D}$. It is indicated that the seabed soil near to the breakwater head is much easier to liquefy than the soil behind the breakwater. At the end of computation, the wave-induced residual pore pressure is about $23 \mathrm{kPa}$ at position $\mathrm{C}$, which is the same with that at position A shown in Figure 5. However, the time to reach this magnitude of residual pore pressure at position $\mathrm{C}$ lags about 35 wave periods. It is indicated that the seabed response in front of the breakwater is much stronger than that near to the breakwater. At position $\mathrm{D}$, the wave-induced residual pore pressure is only $3 \mathrm{kPa}$, which is much smaller than 

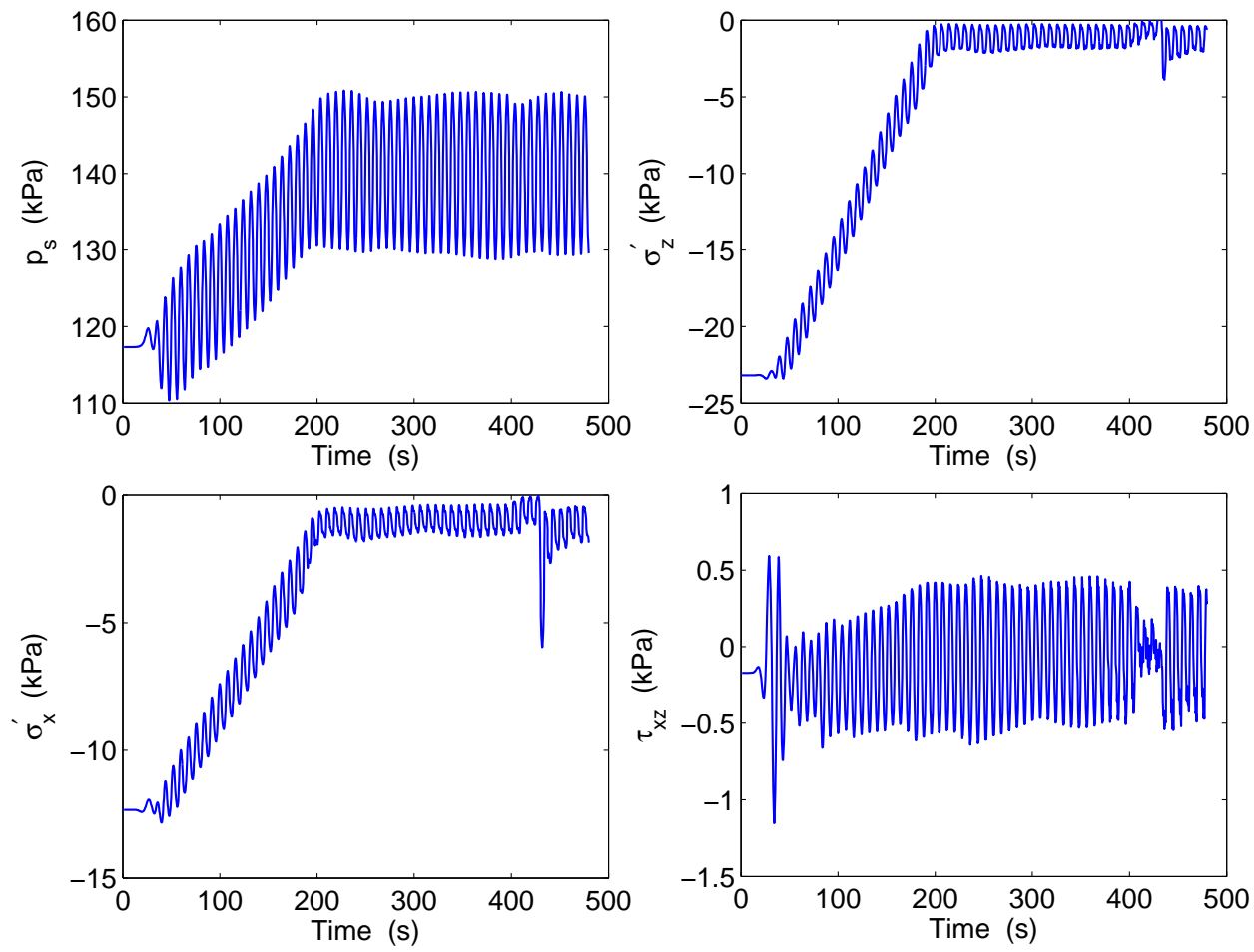

(a) $z=13 \mathrm{~m}$
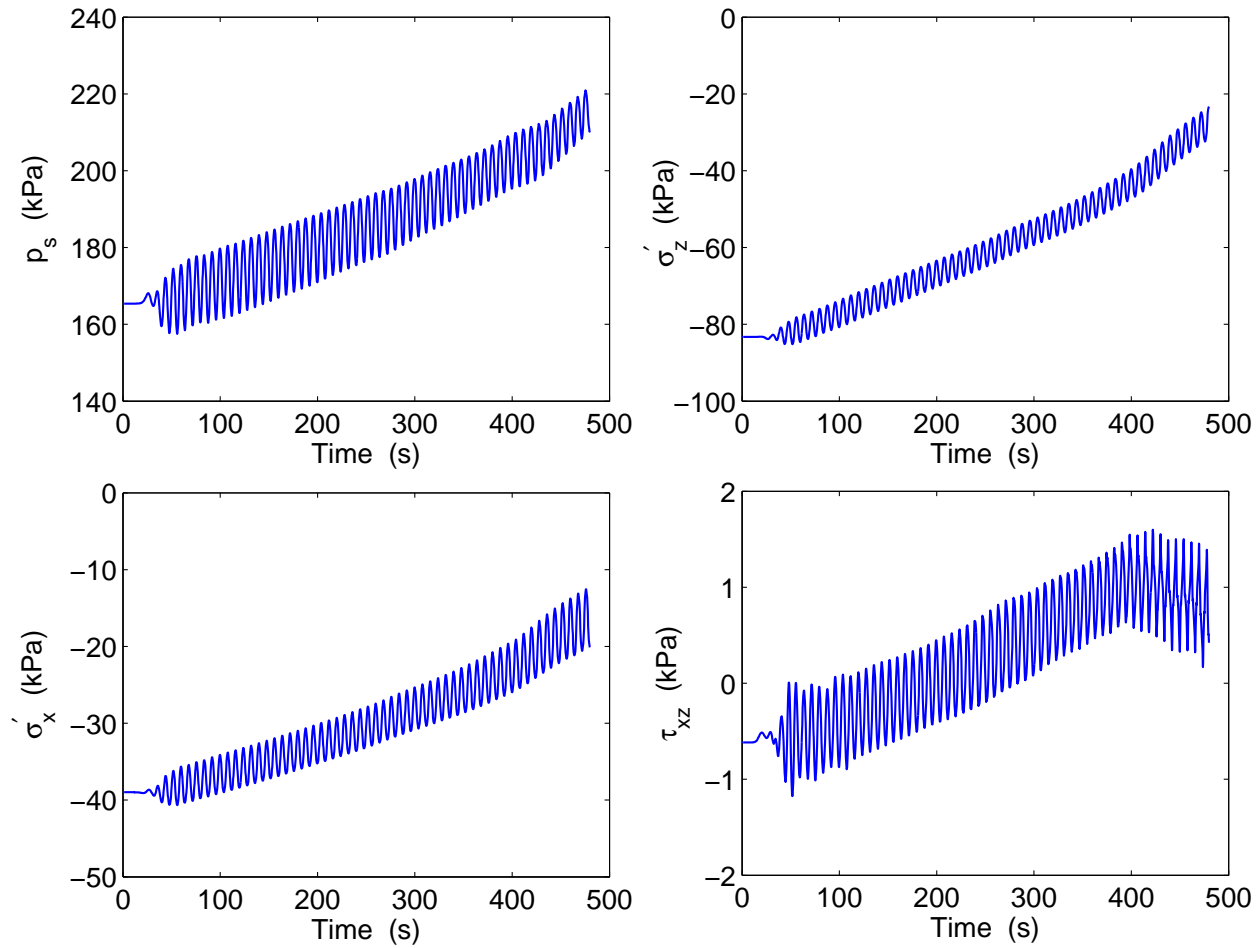

(b) $z=8 \mathrm{~m}$

Figure 5: Pore pressure build up, and effective stresses reduction at typical positions in front of the breakwater due to the standing wave loading. (a): A ( $x=164 \mathrm{~m}, y=85 \mathrm{~m}, z=13 \mathrm{~m})$; (b): B $(x=164 \mathrm{~m}, y=85 \mathrm{~m}, z=8 \mathrm{~m})$. 

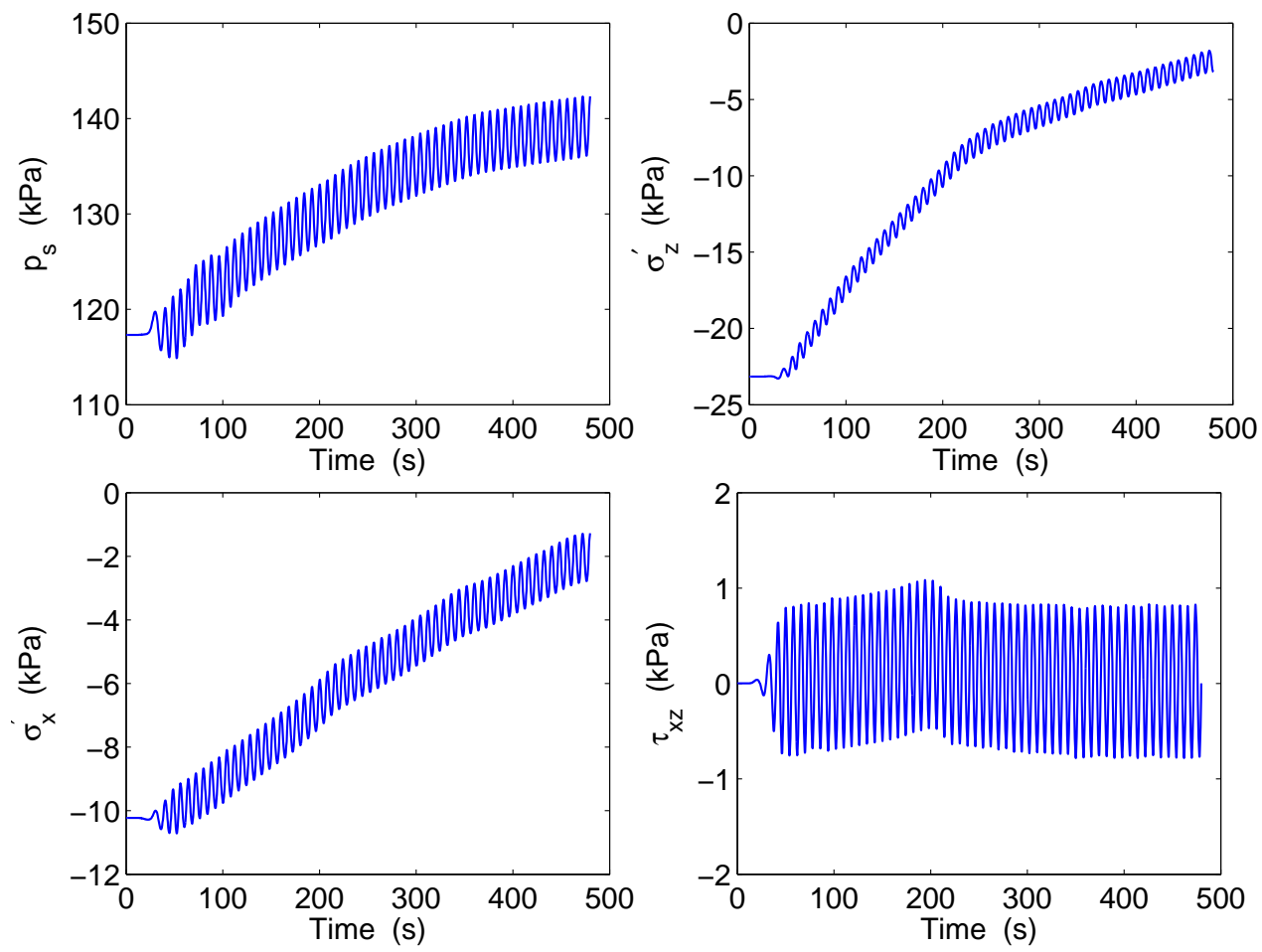

Figure 6: Pore pressure build up, and effective stresses reduction at typical position $\mathrm{C}$ ( $x=205 \mathrm{~m}, y=15 \mathrm{~m}$, $z=13 \mathrm{~m}$ ) near to the breakwater head due to the progressive wave loading.
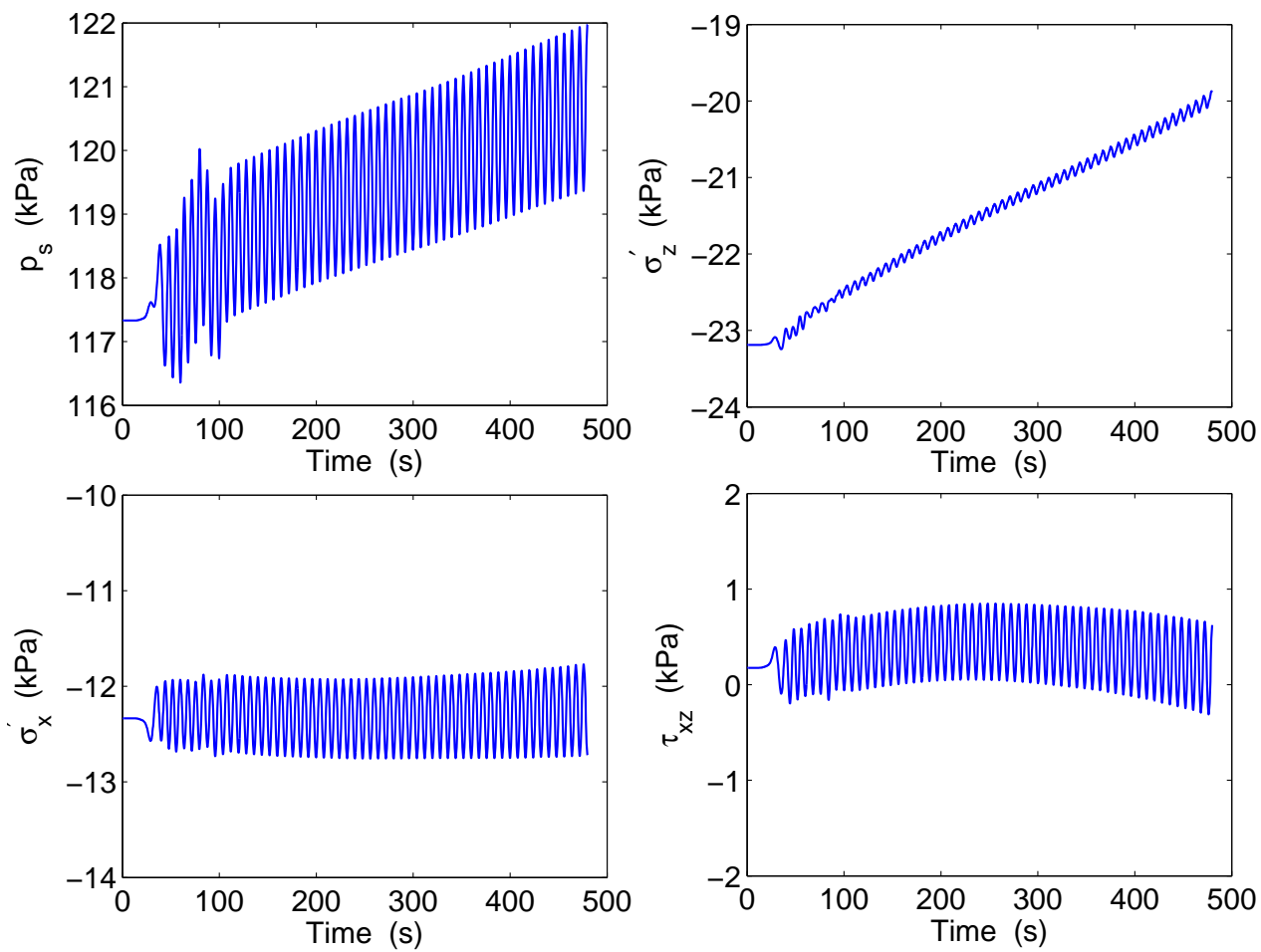

Figure 7: Pore pressure build up, and effective stresses reduction at typical position D ( $x=246 \mathrm{~m}, y=85 \mathrm{~m}$, $z=13 \mathrm{~m}$ ) behind the breakwater due to the diffracted wave loading 

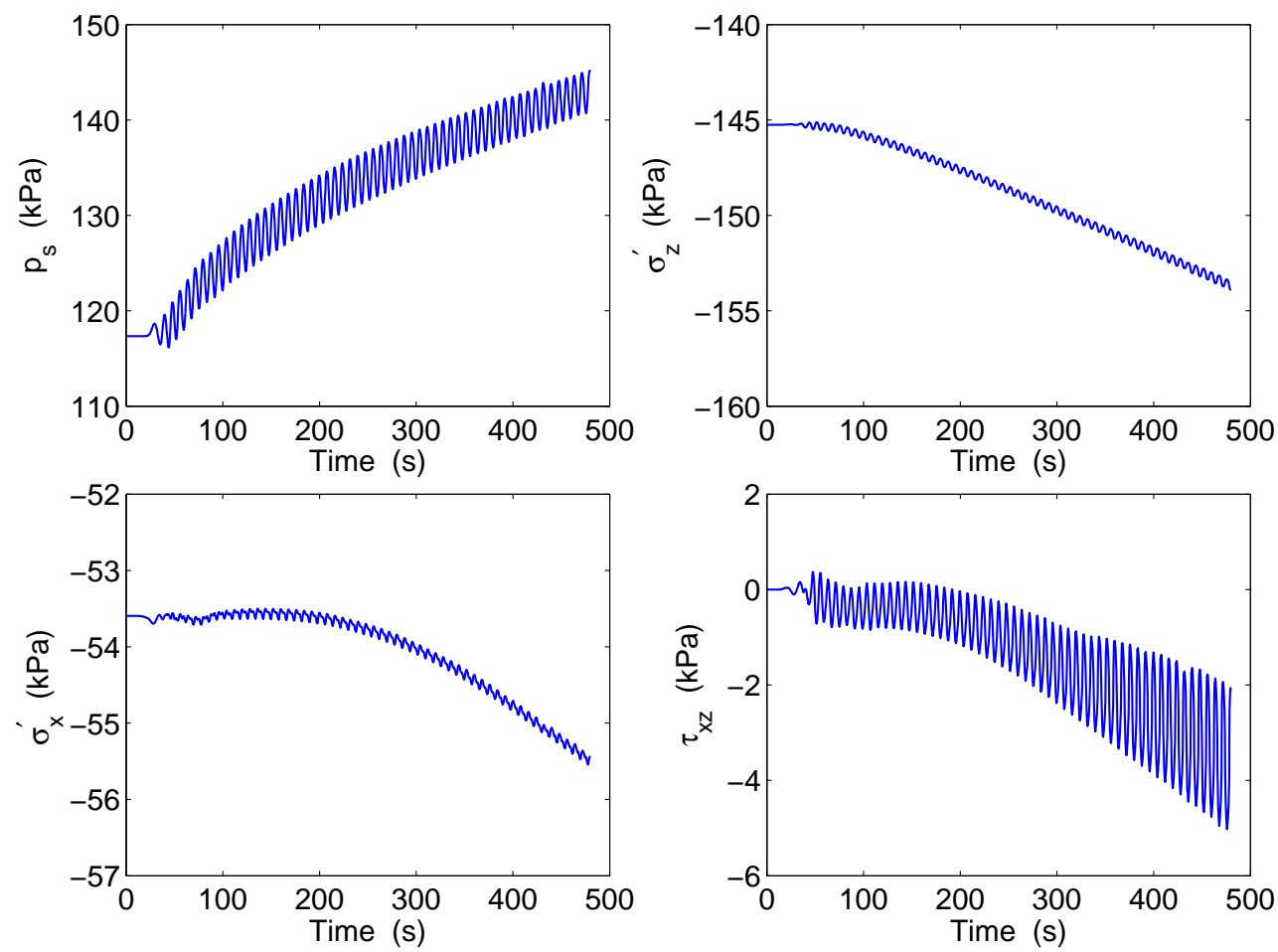

Figure 8: Pore pressure build up, and effective stresses reduction at typical position $\mathrm{E}(x=205 \mathrm{~m}, y=85 \mathrm{~m}$, $z=13 \mathrm{~m}$ ) under the breakwater.

that at $\mathrm{A}$ and $\mathrm{C}$. It is shown that the wave-induced seabed response is weakest behind the caisson breakwater. Comparing with the characteristics of wave field around the caisson breakwater, it is found that the dynamic response of seabed foundation is directly related to the wave field distribution.

It is interesting to reveal the dynamic response of seabed foundation under the caisson breakwater. Obviously, there is no direct wave loading on the seabed surface under the caisson breakwater (contact with the bottom of breakwater). However, the vibration of pore pressure at the interface between the seabed foundation and the caisson breakwater, as well as the wave-induced swaying of the caisson breakwater have significant effect on the seabed dynamics under the caisson breakwater. Figure 8 illustrates the time history of wave-induced pore pressure, effective stress $\sigma_{x}^{\prime}, \sigma_{z}^{\prime}$, and shear stress $\tau_{x z}$ at the representative position $\mathrm{E}$ beneath the caisson breakwater. It can be seen that the pore pressure also builds up. The wave-induced residual pressure reaches up to $26 \mathrm{kPa}$, which is actually greater than that at position A and $\mathrm{C}$ even they have the same buried depth. However, the effective stresses and shear stress in seabed foundation under the caisson breakwater increase in the process of wave loading at the meantime. This phenomenon is completely different with that in other zones around the caisson breakwater. The reason for this phenomenon is attributed to the effect of swaying and tilting of breakwater. As mentioned in above section, wave impact acting on the lateral sides of the caisson breakwater makes the breakwater built on loose seabed foundation sway. The swaying of breakwater makes 
the soil particles beneath it rearranges more easily accompanying the pore water drainage, and makes the soil particles contact with each other more densely. Soil compaction due to the rearrangement of soil particles makes the pore pressure under the breakwater builds up. At the meantime, the offset to $-x$ direction of gravity center, as well as gravity compression of breakwater makes the contact effective stresses, and shear stresses between soil particles at position E become greater and greater. This highly nonlinear phenomenon also has been observed more clearly in Ye and Wang (2015) and Ye et al. (2016a).

Figure 9 demonstrates the distribution of wave-induced excess pore pressure and corresponding dynamic effective stresses in the loose seabed foundation at time $t / T=60$. In Figure 9 , it is found that wave-induced pore pressure in the zones under the nodes of standing wave is much higher than that in the zones under the antinodes of standing wave in front of the caisson breakwater; the influence depth of the standing wave is much deeper than that of the progressive wave near to the breakwater head. It is also can be seen that diffracted waveinduced pore pressure is smallest behind the caisson breakwater. It is indicated that protection of the caisson breakwater for the seabed behind it is effective. In the regions where pore pressure significantly building up, the wave-induced dynamic effective stress $\sigma_{x}^{\prime}, \sigma_{y}^{\prime}$ and $\sigma_{z}^{\prime}$ are tensile (positive value). It means that the effective stresses reduce significantly, and potentially reach or approach liquefaction state. Attention is paid to the zone under the caisson breakwater. It is clearly observed that there is a high residual pore pressure zone beneath the breakwater; however, the dynamic effective stresses in this zone is not tensile, but compressive (negative value). It is again indicated that soil particles under the caisson breakwater contact more densely relative to its initial consolidation state.

\section{Progressive liquefaction in seabed foundation}

\subsection{Definition of progressive liquefaction and criterion}

It is well known that there are two kinds of mechanism for sand liquefaction corresponding to dense seabed (poro-elastic) and loose seabed (poro-elastoplastic): momentary liquefaction and residual liquefaction. The momentary liquefaction only can occur in very dense seabed. In this section, wave-induced residual liquefaction in loose seabed foundation around the caisson breakwater is investigated. The essence of residual liquefaction of sand bed is that soil particles are loosely deposited in offshore area. Under cyclic loading, such as ocean wave or seismic wave, soil particles trend to rearrange their relative positions, resulting in pore pressure build up, and effective stress reduction in soil if the drainage of pore water is poor. When wave-induced residual pore pressure is sufficient to make the contact effective stresses between soil particles become zero, 

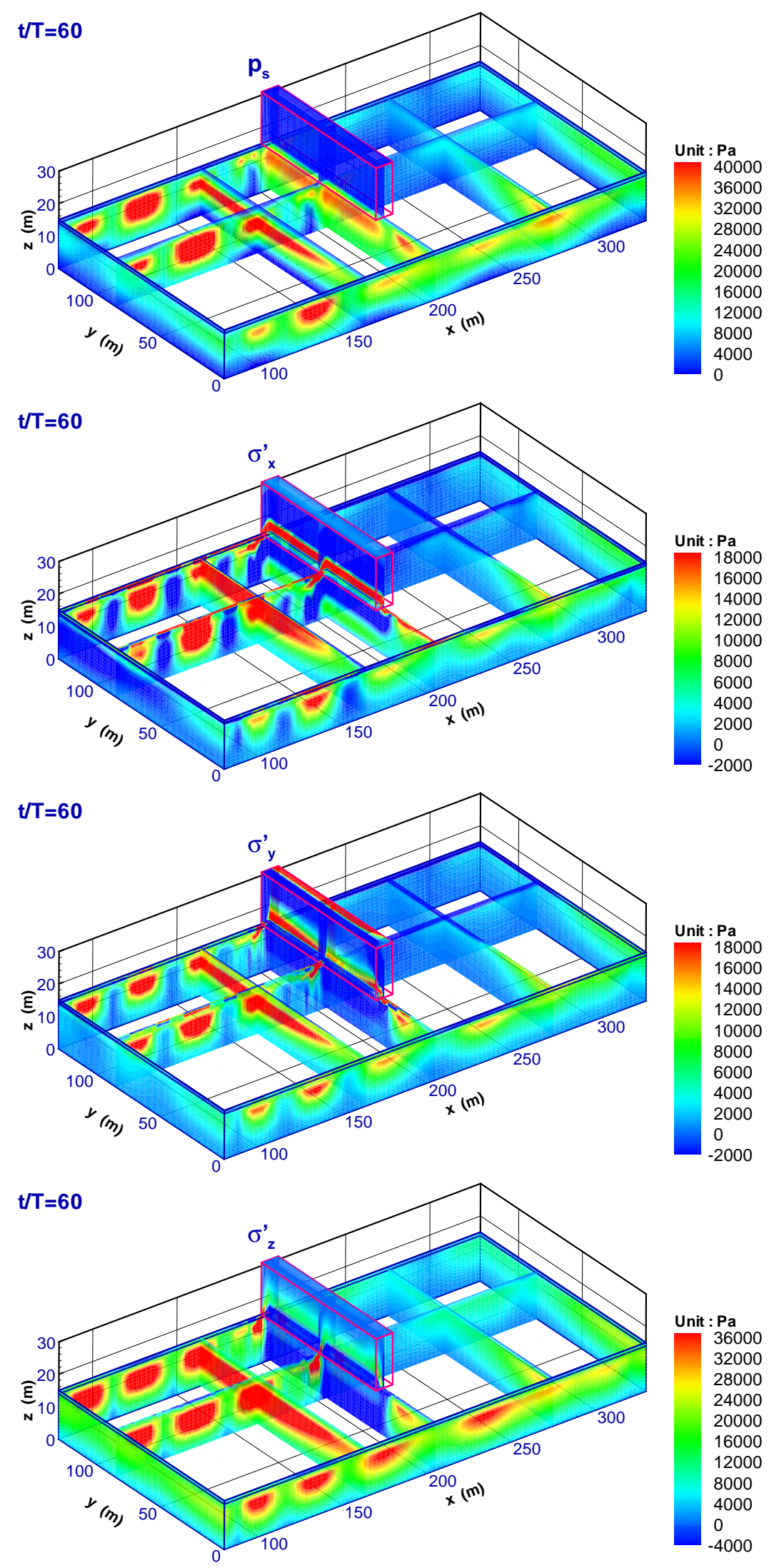

Figure 9: Distribution of the 3D wave-induced excess pore pressure and the corresponding dynamic effective stresses in the seabed foundation at time $t / T=60$. 


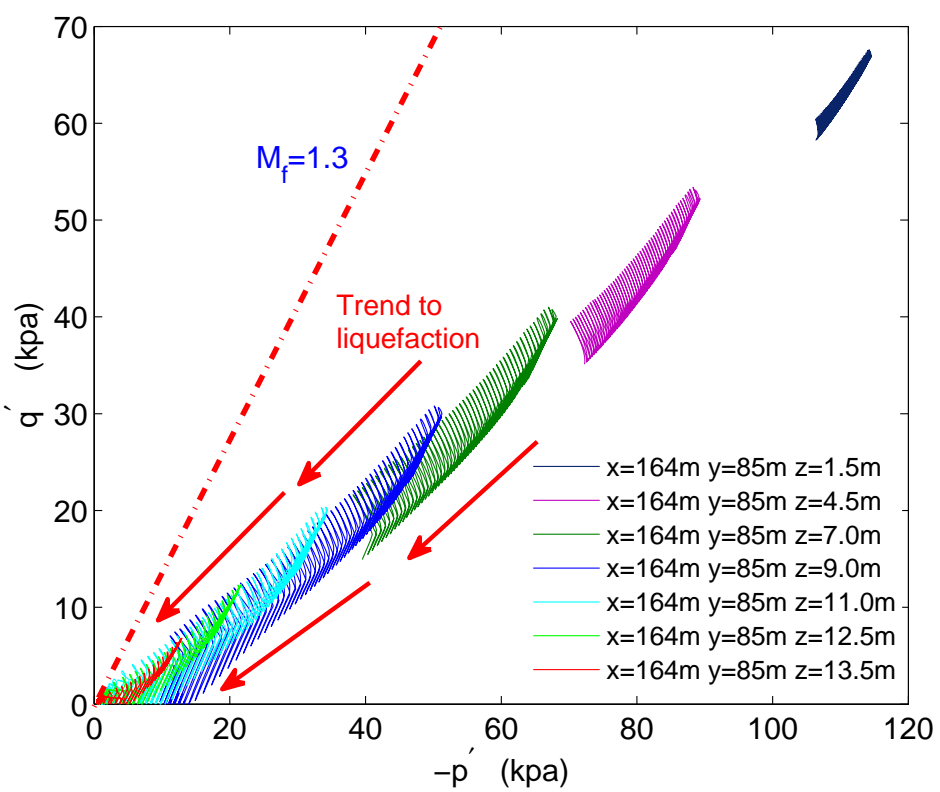

Figure 10: Stress path along the depth of seabed foundation on line $x=164 \mathrm{~m}, y=85 \mathrm{~m}$ (in front of the caisson breakwater). $M_{f}$ is the slope of the yield surface on $p^{\prime}-q^{\prime}$ plane.

seabed soil becomes liquefied. The wave-induced residual liquefaction in sand bed does not appear and disappear periodically like the momentary liquefaction, but is a progressive process. This progressive liquefaction process has been observed in a centrifuge test by Sassa and Sekiguchi (1999). The liquefaction in loose seabed first occurs at the surface of seabed; then, the frontier of liquefaction zone advances downward gradually under wave loading.

Soil liquefaction is actually a process for effective stresses to reduce and approach zero stress state. Generally, liquefaction process can be reflected by stress path plotting. Fiugre 10 shows the stress paths along the depth of the loose seabed foundation on line $x=164 \mathrm{~m}, y=85 \mathrm{~m}$ (in front of the caisson breakwater). It is observed that the magnitude of initial stress has positive relation with buried depth; and the mean effective stress $p^{\prime}$ and deviatoric stress $q^{\prime}$ both reduce in the process of wave loading. At the end of computation, only the soil in the upper seabed can reach the zero stress state. The soil in the lower seabed is far away from liquefaction state.

Figure 11 illustrates the stress paths on four typical points around the caisson breakwater on the plane $z=11 \mathrm{~m}$. It is clearly observed that the mean effective stress $p^{\prime}$ and deviatoric stress $q^{\prime}$ at the point in front of the breakwater gradually reduce, and finally reach liquefaction state under standing wave loading. $p^{\prime}$ and $q^{\prime}$ at the points near to the breakwater head, and behind the breakwater also reduce; however, they are finally still far away from the zero stress state. It is interesting to point out that $p^{\prime}$ is reduced; while $q^{\prime}$ is increased at the position under the breakwater. The reduction of $p^{\prime}$ is due to the pore pressure build up, as illustrated in 

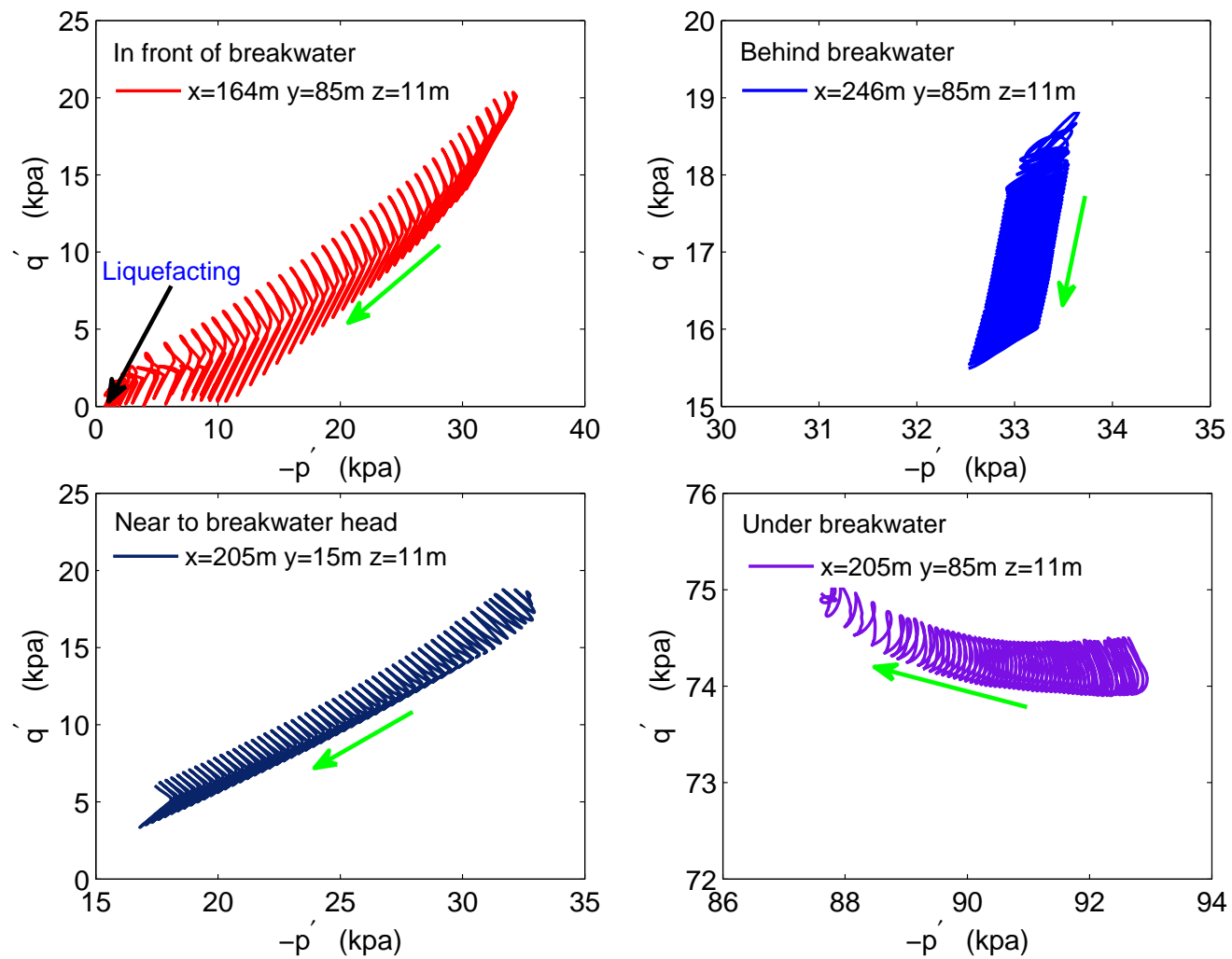

Figure 11: Stress path on four typical points in the seabed foundation around the caisson breakwater on the horizontal plane $z=11 \mathrm{~m}$.

Figure 8; the increasing of $q^{\prime}$ is due to the swaying and tilting of the breakwater. The seabed soil at position E contributes more and more bearing capacity to support its overlying breakwater.. It is indicated that the soil under the caisson breakwater is unlikely to liquefy due to the compression of the breakwater.

$$
\sigma_{z}^{\prime}+2\left(c-\sigma_{x}^{\prime} \tan \phi\right) u\left(-\sigma_{x}^{\prime}\right)+2\left(c-\sigma_{y}^{\prime} \tan \phi\right) u\left(-\sigma_{y}^{\prime}\right) \geq 0
$$

in which $u(x)$ is the unit step function

$$
u(x)= \begin{cases}1 & x>0 \\ 0 & x \leq 0\end{cases}
$$

where $c$ and $\phi$ is the cohesion and internal friction of soil. $\sigma_{x}^{\prime}, \sigma_{y}^{\prime}$ and $\sigma_{z}^{\prime}$ are the current effeictive stress (compression is negative). For sandy soil, its cohesion $c$ normally is 0 . Ye (2012) claims that the 3D liquefaction criterion proposed by Tsai (1995) is a special form of the above proposed liquefaction criterion when $c=0$ and $\phi=26.6^{\circ}$. However, the above liquefaction criteria considering friction between soil particles is only established 
for momentary liquefaction. For residual liquefaction, friction between soil particles actually has no contribution to liquefaction resistance in loose seabed soil; while cohesion has significant contribution to residual liquefaction resistance, for example, clay soil generally is difficult to be liquefied even residual pore pressure has exceeded initial vertical effective stress $\sigma_{0}^{\prime}$. Based on this mechanism, and considering $\sigma_{z}^{\prime}=\sigma_{z 0}^{\prime}+\sigma_{z d}^{\prime}$, where $\sigma_{z 0}^{\prime}$ is the initial vertical effective stress, and $\sigma_{z d}^{\prime}$ is the wave-induced dynamic vertical effective stress, the residual liquefaction potential is defined as

$$
L_{\text {potential }}=\frac{\sigma_{z d}^{\prime}}{-\sigma_{z 0}^{\prime}+\alpha c}
$$

where $\alpha$ is a material coefficient. Due to the fact that macroscopic cohesion $c$ of seabed soil is not absolutely equivalent to the microscopic liquefaction resistance of soil particles, a material coefficient must be added to cohesion $c$ of soil in Equation (3). Currently, investigation on the effect of cohesion of soil on its liquefaction resistance is limited. As a result, the value of material coefficient $\alpha$ is not sure. This will be a interesting topic in the future.

In theory, when $L_{\text {potential }}$ is greater than or equal to 1.0 at a position, the soil is liquefied at this position. Obviously, liquefaction potential of soil would be overestimated if the cohesion of soil are not taken into consideration in analysis. But actually, $L_{\text {potential }}$ will never exceed 1.0 either in numerical computation or in laboratory tests (Ishihara, 1993; Wu et al., 2004). The reason is that sand soil is non-cohesive granular material. It can not bear any tensile stress. Therefore, a sandy soil can not reach the complete liquefied state in numerical computation. Namely, the ratio between excess residual pore pressure and liquefaction resistance of soil can not reach 1.0. Ishihara (1993) suggested that the pore water pressure ratio $\left(p_{\text {excess }} / \sigma_{0}^{\prime}\right)$ in silty sands or sandy silts containing some amount of fines was observed not to develop fully, but instead may stop building up when it has reached a value equal to about 0.9 to 0.95 of liquefaction resistance. If liquefaction was strictly defined as the occurrence of liquefaction potential being equal to 1.0, then these soils would never 'liquefy' despite of the fact that they may have behaved as a liquefied materials. Some laboratory soil tests (Wu et al., 2004; Kammerer et al., 2002; Wu et al., 2003) performed at U.C. Berkeley also shown that liquefaction still could occur when the excess residual pore pressure did not reach the initial vertical effective stress. It means that liquefaction is highly possible to occur even if $L_{\text {potential }}<1.0$. Based on this point, we assume that a soil will liquefy if $L_{\text {potential }} \geq \alpha_{r} . \alpha_{r}$ is a coefficient depending on soil characteristics. Its range generally is 0.78-0.99 (Wu et al., 2004). Accordingly, liquefaction resistance of a soil can be defined as $L_{r}=\alpha_{r}\left(-\sigma_{z 0}^{\prime}+\alpha c\right)$. In this study, due to the fact that the seabed foundation is assumed as sandy soil, cohesion $c$ is 0 . 


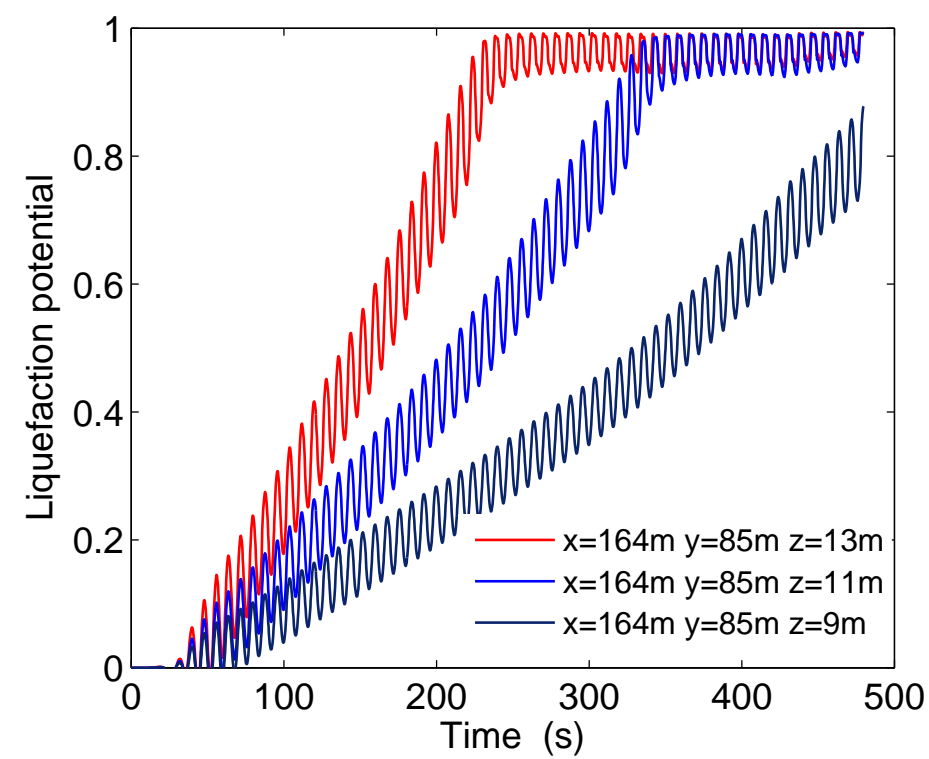

Figure 12: Liquefaction potential at typical position on line $(x=164 \mathrm{~m}, y=85 \mathrm{~m})$ in front of the breakwater (noted: passing through position A and B)

From the point of view of engineering design, the coefficient $\alpha_{r}$ also can be deemed as the maximum allowable degree of liquefaction resistance capacity of a soil, for example, $\alpha_{r}$ could be set as 0.8 in the design of engineering structures. It means that if the degree of liquefaction resistance capacity of seabed foundation is greater than 0.8 , coastal engineers involved in design could think the seabed foundation can not support its overlying structures no longer; and overlying offshore structures would lose their instability. In the practice of design engineering, it is highly suggested to set a maximum allowable degree of liquefaction resistance capacity for seabed foundation from case to case according to actual situation.

\subsection{Progressive liquefaction prediction}

Adopting the definition of liquefaction potential in Equation(3), the wave-induced residual liquefaction in the seabed foundation around the caisson breakwater is evaluated.

Figure 12, 13 and 14 illustrate the time history of wave-induced residual liquefaction potential at some typical positions around the breakwater. In Figure 12, it can be seen that wave-induced residual liquefaction potential in loose seabed foundation gradually increases until reaching a value near to 1.0. However, residual liquefaction potential at the three typical positions never equals to 1.0. Another phenomenon observed in Figure 12 is that the time for residual liquefaction potential reaching its highest value along the depth of seabed foundation is significantly different. The time needed for residual liquefaction potential to reach its highest value is positively related to buried depth of soil. For example, the time is about 230 s for $L_{\text {potential }}$ reaching 


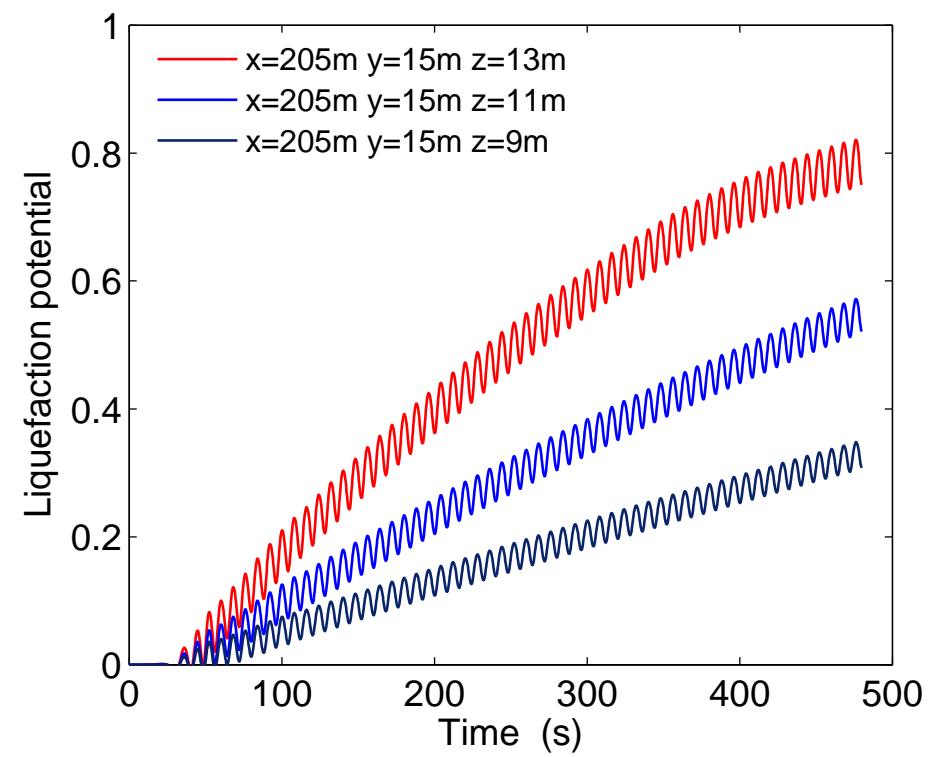

Figure 13: Liquefaction potential at typical positions on line ( $x=205 \mathrm{~m}, y=15 \mathrm{~m})$ near to the head of the breakwater (noted: passing through position C)

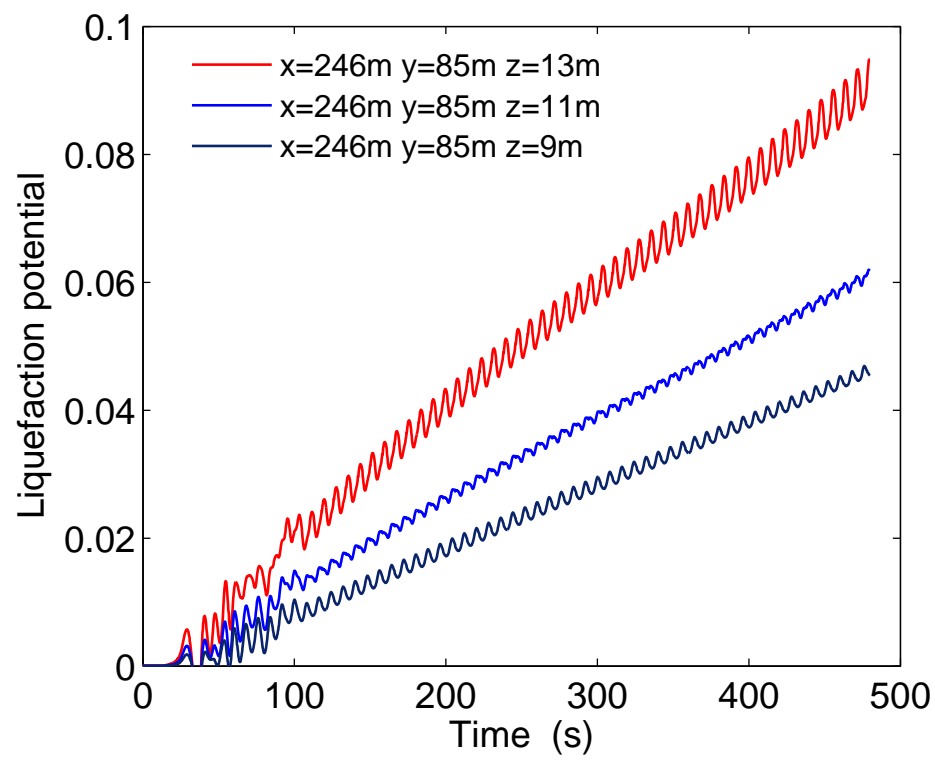

Figure 14: Liquefaction potential at typical positions on line ( $x=246 \mathrm{~m}, y=85 \mathrm{~m})$ behind the breakwater (noted: passing through position D) 


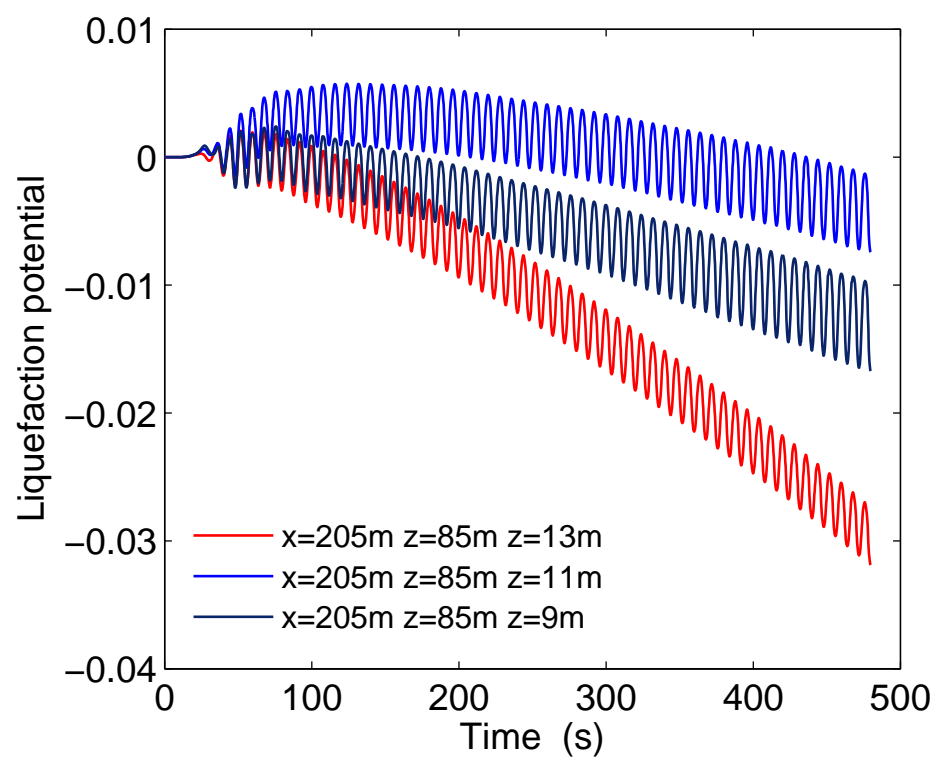

Figure 15: Liquefaction potential at typical positions on line $(x=205 \mathrm{~m}, y=85 \mathrm{~m})$ under the caisson breakwater (noted: passing through position E)

its highest value when the buried depth is $2 \mathrm{~m}(z=13 \mathrm{~m})$; while it is about $330 \mathrm{~s}$ when the buried depth is $4 \mathrm{~m}$ $(z=11 \mathrm{~m})$. Until time $t=480 \mathrm{~s}$, liquefaction potential does not reach the highest value when the buried depth is $6 \mathrm{~m}(z=9 \mathrm{~m})$. This characteristics of liquefaction in the seabed foundation in front of the caisson breakwater is the symbol of wave-induced progressive liquefaction.

Figure 13 and 14 indicate that residual liquefaction potential in the seabed foundation near to the breakwater head, and behind the caisson breakwater is significantly less than that in front of the breakwater at the same time. At time $t=480 \mathrm{~s}$, residual liquefaction potential at position $\mathrm{C}(x=205 \mathrm{~m}, y=15 \mathrm{~m}, z=13 \mathrm{~m})$ (near to the head of breakwater ) is only about 0.8 ; and it is only less than 0.1 at position $\mathrm{D}(x=246 \mathrm{~m}, y=85 \mathrm{~m}, z=13 \mathrm{~m})$ (behind the breakwater). Both of them are far away from the liquefaction state. This attributes to the different wave fields around the caisson breakwater.

Figure 15 demonstrates the time history of wave-induced residual liquefaction potential at three typical positions under the caisson breakwater. It is clearly observed that wave-induced residual liquefaction under the caisson breakwater is negative value. It means that the wave-induced dynamic effective stresses under the caisson breakwater is compressive (negative value). Actually, the reason for this phenomenon has been analyzed in when analyzing Figure 11 and Figure 8. In short, seabed foundation under the caisson breakwater is unlikely to liquefy due to the gravity compression of the caisson breakwater.

In the above analysis, it has been recognized that wave-induced residual liquefaction in the seabed foundation is a progressively downward process . Figure 16 illustrates the progressive liquefaction process on typical 


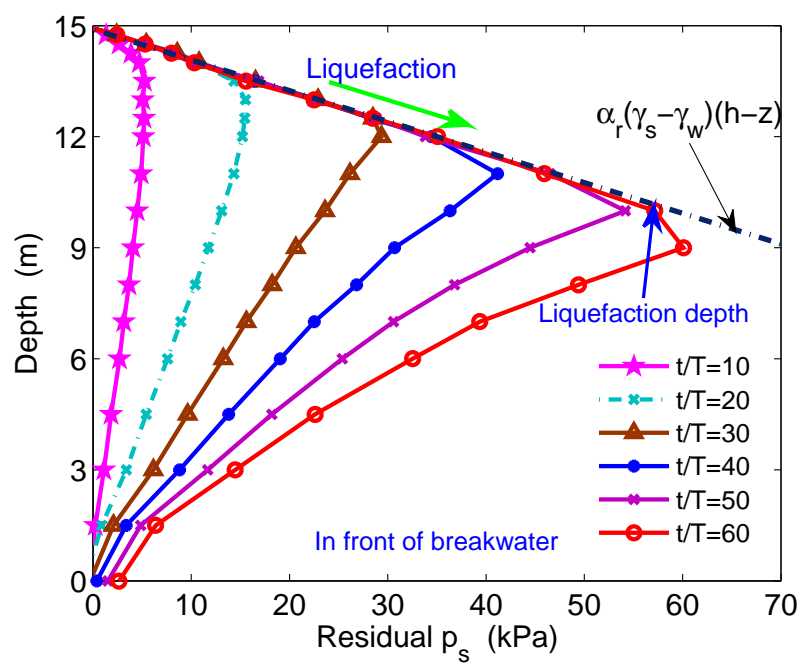

(a) In front of the breakwater $(x=164 \mathrm{~m}, y=85 \mathrm{~m})$

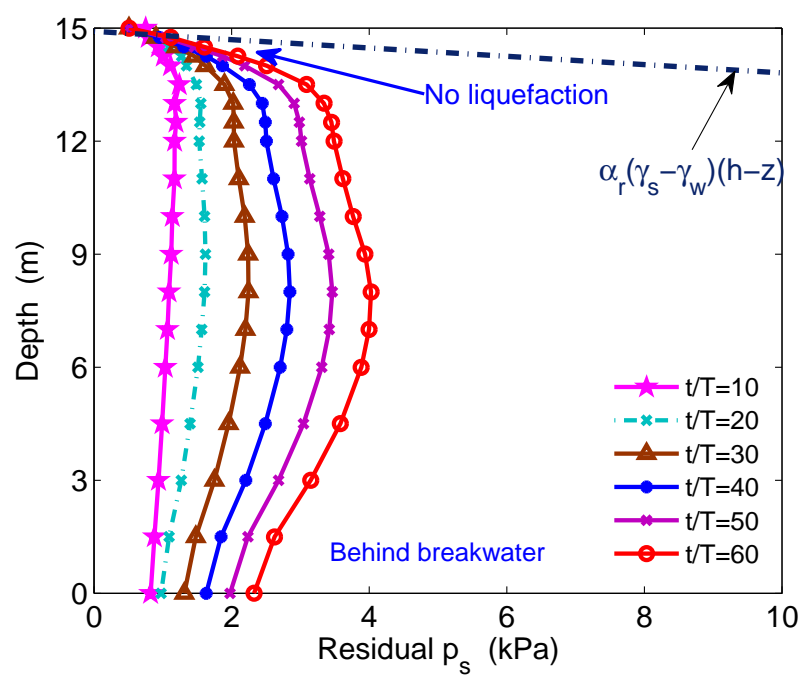

(c) Behind the breakwater ( $x=246 \mathrm{~m}, y=85 \mathrm{~m})$

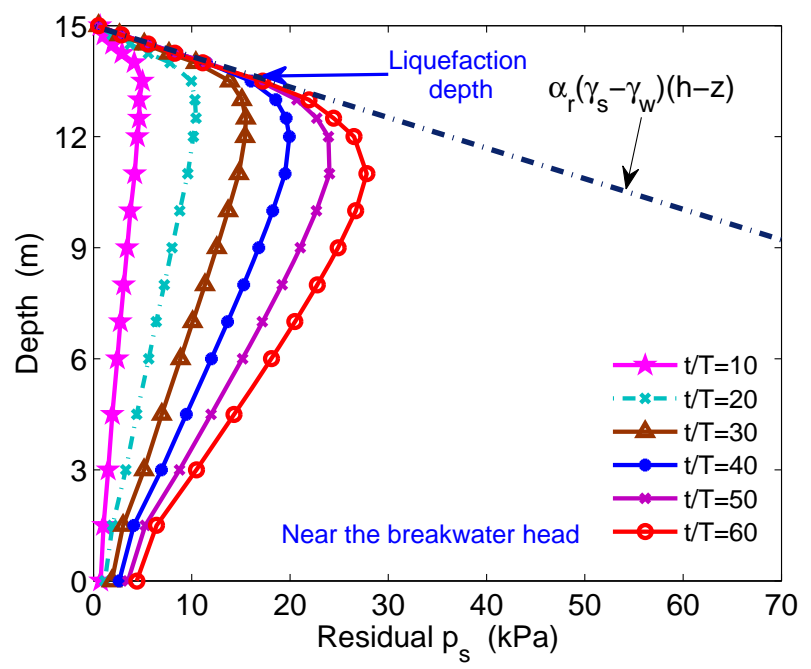

(b) Near to the breakwater head ( $x=205 \mathrm{~m}, y=15 \mathrm{~m})$

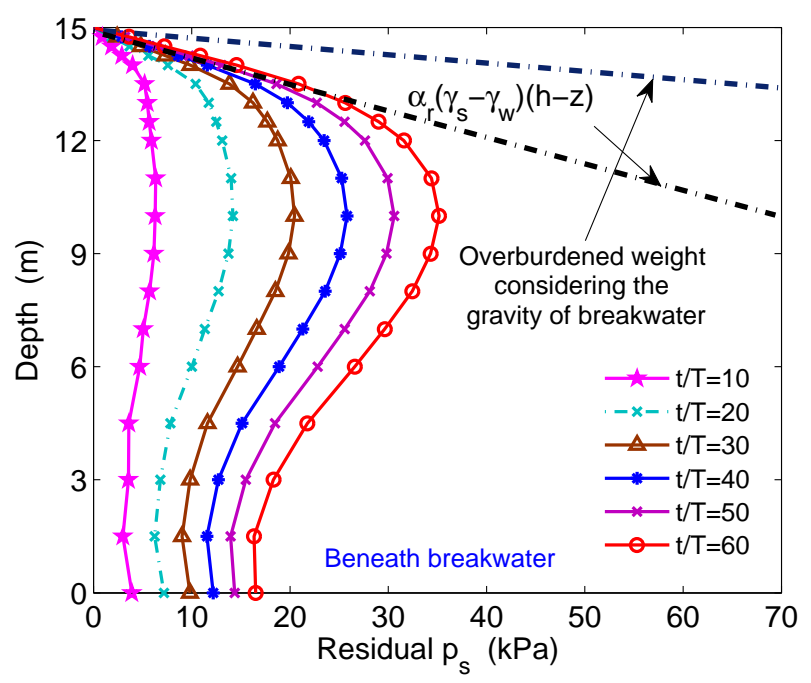

(d) Under the breakwater $(x=205 \mathrm{~m}, y=85 \mathrm{~m})$

Figure 16: Distribution of the wave-induced residual pore pressure along the depth of the seabed foundation on typical vertical lines around the caisson breakwater at different time. Based on the slope of the liquefaction resistance line in (a) and (b), the coefficient $\alpha_{r}$ is determined as 0.98 for Nevada dense sand. 
vertical lines in the seabed foundation around the caisson breakwater. It is found that wave-induced residual pore pressure builds up with the time of wave loading. However, the build-up of residual pore pressure is subjected to certain constraits. It can not increase indefinitely. There is a line (referred as liquefaction resistance line $L_{r}$ ) in the graphs to show the constrait for the development of residual pore pressure. According to the definition of $L_{r}$, this line depends on the initial/current stress state in sand soil. Residual pore pressure can not exceed liquefaction resistance line $L_{r}$. When wave-induced residual pore pressure at a position reaches to liquefaction resistance line, it means that the wave-induced excess residual pore pressure overcomes the liquefaction resistance of soil. The soil at this position becomes liquefied at this moment.

In Figure 16 (a), it is clearly observed that wave-induced liquefaction in the seabed foundation in front of the caisson breakwater is a progressive process. The frontier of liquefaction zone in the seabed foundation advances downward gradually, for example, the liquefaction depth is $1.5 \mathrm{~m}, 3.0 \mathrm{~m}$ and $4.0 \mathrm{~m}$, respectively when at time $t / T=20, t / T=30$ and $t / T=50$. The progressive liquefaction process on the vertical line $(x=165 \mathrm{~m}$, $y=85 \mathrm{~m}$ ) is illustrated in Figure 17. It is clearly shown that the frontier of liquefaction zone progressively moves downward under long-term wave loading. In Figure 16 (b), it is observed that the maximum liquefaction depth in the seabed near to the breakwater head is only $1.5 \mathrm{~m}$ when $t / T=60$, which is much less than that in front of the breakwater. Obviously, the reason for this is that standing wave in front of the breakwater is much stronger than the progressive wave. For the seabed foundation behind the breakwater, the diffracted waveinduced residual pore pressure maximumly is only $4 \mathrm{kPa}$, which is far away from the liquefaction resistance line. The seabed foundation behind the caisson breakwater can not liquefy. Here, the attention is also paid to the seabed foundation beneath the caisson breakwater. In Figure 16 (d), it is observed that residual pore pressure in the seabed foundation under the breakwater also significantly increase in the process of wave loading. The maximum residual pore pressure can reach up to about $35 \mathrm{kPa}$ in the upper seabed. However, due to the gravity compression of the breakwater, the liquefaction resistance of soil beneath the breakwater significantly increases. The residual pore pressure can not reach the liquefaction resistance line beneath the caisson breakwater. Therefore, it is again shown that seabed soil under the caisson breakwater can not liquefy.

Figure 18 shows the distribution of wave-induced liquefaction potential along the depth of seabed foundation around the caisson breakwater at time $t / T=60$. It is clearly observed that wave-induced liquefaction potential in the upper seabed is greater than that in the lower seabed. In the seabed foundation beneath the caisson breakwater ( $x=205 \mathrm{~m}, y=85 \mathrm{~m}$ ), the liquefaction potential is less than 0.0 . It is indicated that the seabed under the caisson breakwater can not liquefy. In the other seabed foundation around the caisson breakwater, the liquefaction potential in front of the breakwater is greatest; and it is smallest behind the breakwater. According to the maximum liquefaction depth in front of the breakwater at time $t / T=60$ determined in Figure 16 


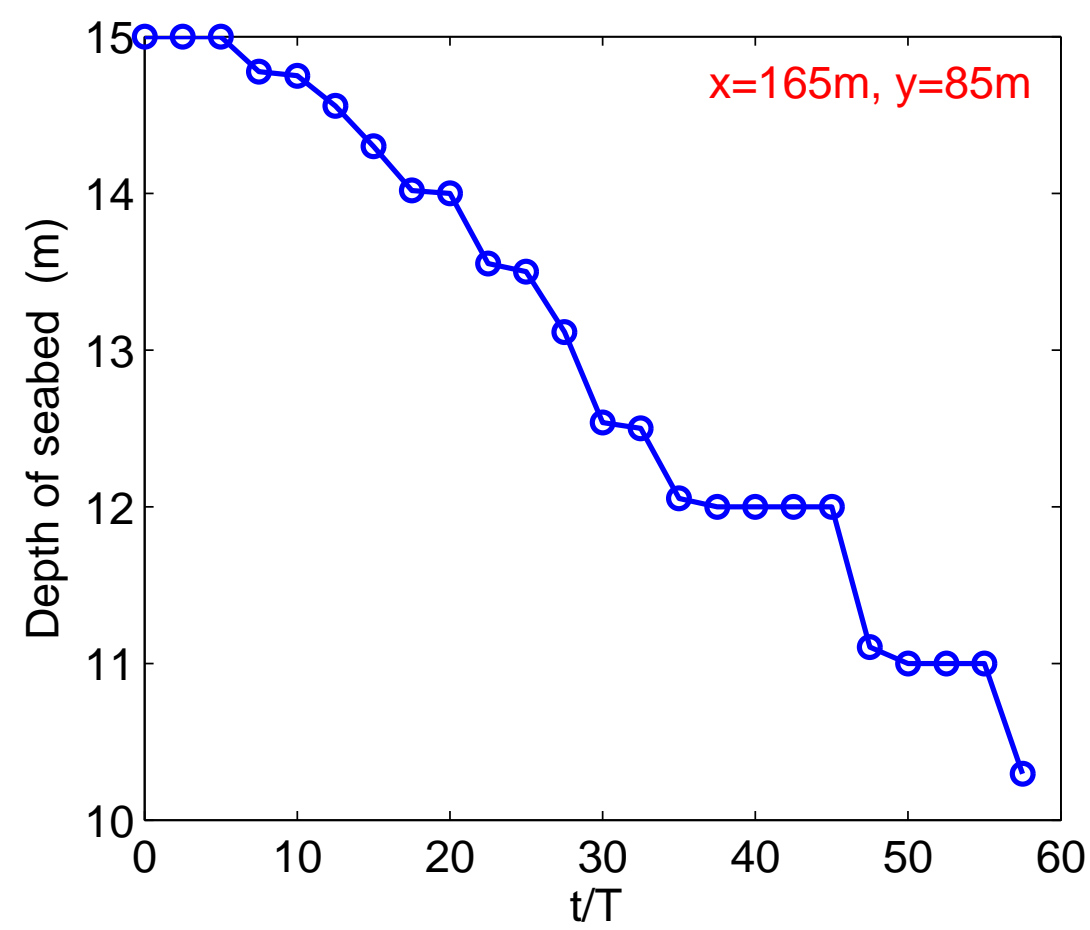

Figure 17: Wave-induced progressive liquefaction process of seabed foundation at ( $x=165 \mathrm{~m}, y=85 \mathrm{~m}$ ). It is shown that the frontier of liquefaction zone progressively moves downward from the seabed surface.

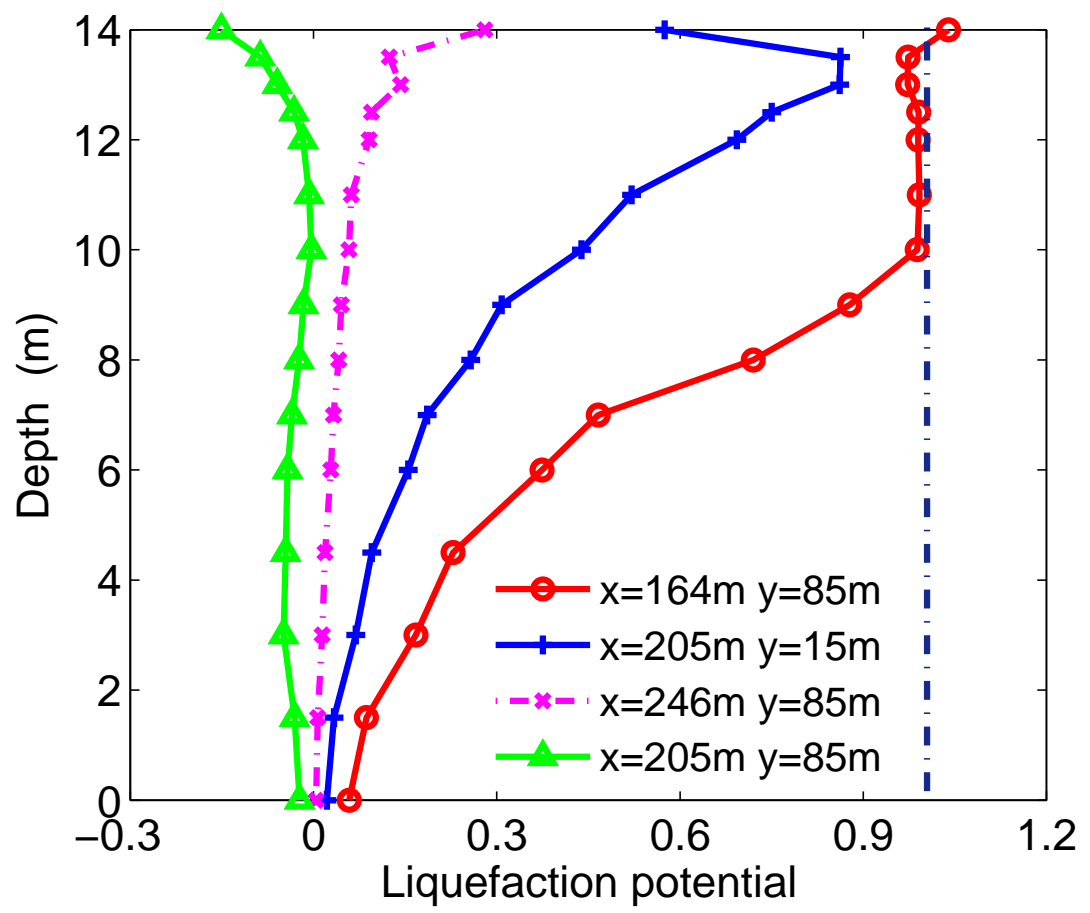

Figure 18: Distribution of the wave-induced liquefaction potential along the depth of the seabed foundation around the caisson breakwater at time $t / T=60$. The coefficient $\alpha_{r}$ is also determined as 0.98 according to the maximum liquefaction depth in the seabed in front of the caisson breakwater. 
(a), coefficient $\alpha_{r}$ is again determined as 0.98. This value of $\alpha_{r}$ is only valid for Nevada dense sand. For other types of sand bed, $\alpha_{r}$ should be individually determined.

Figure 19 shows the distribution of wave-induced residual liquefaction potential in the seabed foundation on the plane $z=12.5 \mathrm{~m}$ at time $t / T=20,40$ and 60. As illustrated in Figure 19, residual liquefaction potential in the seabed foundation at time $t / T=60$ is significantly greater than that at time $t / T=20$ and 40 . It is indicated that pore pressure in the seabed foundation significantly builds up from time $t / T=20$ to 60 . In Figure 19, it also can be seen that residual liquefaction potential behind the caisson breakwater is much less than that in front of the caisson breakwater at the same time. This phenomenon has also been recognized in the above analysis. The residual liquefaction potential in the seabed foundation under the caisson breakwater is less than zero at time $t / T=20,40$ and 60 . This attributes to the fact that the gravity of breakwater compresses the soil beneath it, and makes it is unlikely for the inter-granular effective stresses to reach zero.

Another interesting phenomenon observed in Figure 19 is that the zones with high and low liquefaction potential appear alternatively in front of the breakwater. This can be attributed to the wave in front of the breakwater is standing wave resulted from the interference between incident wave and reflected wave. Under the nodes of standing wave, the liquefaction potential is high; while it is low under the anti-nodes of standing wave.

\section{Effect of the direction of breakwater}

The angle between incident wave and the caisson breakwater is set as $\theta=60^{\circ}$ and $\theta=120^{\circ}$, respectively. The 3D waves fields are generated by wave maker adopting the same wave characteristics with the case when $\theta=90^{\circ}: H=1.5 \mathrm{~m}, d=10 \mathrm{~m}$, and $T=8.0 \mathrm{~s}$. The wave field in front of the caisson breakwater is short-crested wave, rather than standing wave if incident waves obliquely propagating to the caisson breakwater. The waveinduced force per meter length acting on the front lateral side of the breakwater is also much smaller than that if the breakwater is perpendicular with incident wave. Different wave fields around the caisson breakwater directly lead to different distribution of residual liquefaction zone in the seabed foundation around the caisson breakwater.

Figure 20 and 21 show the 3D distribution of wave-induced residual liquefaction potential on the plane $z=12.5 \mathrm{~m}$ in the seabed foundation around the caisson breakwater when $\theta=60^{\circ}$ and $\theta=120^{\circ}$, respectively. Some the same phenomena can be observed when $\theta=90^{\circ}$. Residual liquefaction potential in the seabed foundation increases with the time of wave loading. Residual liquefaction potential in the seabed foundation when $t / T=60$ is significantly greater than that when $t / T=20$ and 40 , and residual liquefaction potential behind the caisson 

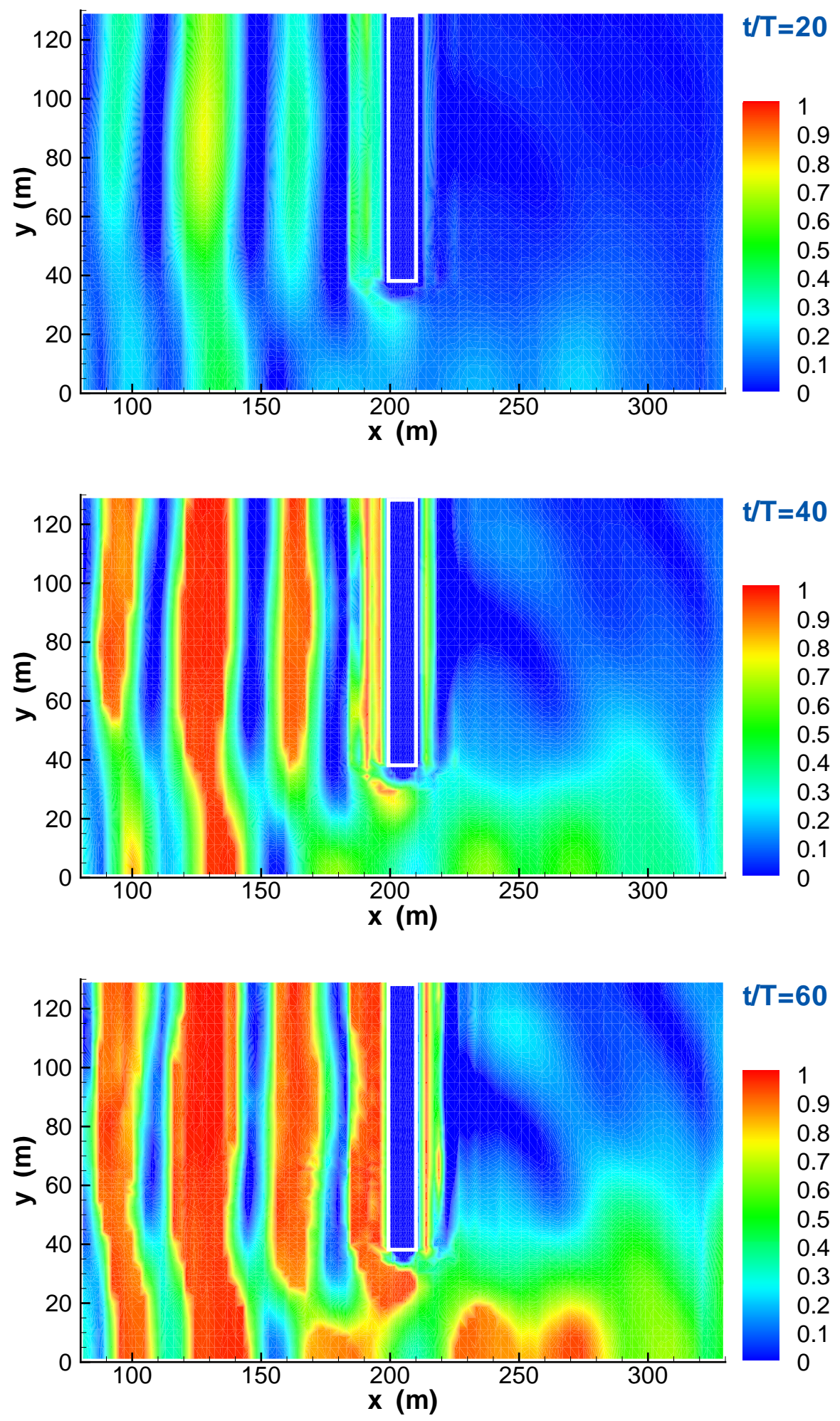

Figure 19: Distribution of liquefaction potential in the seabed foundation on $z=12.5 \mathrm{~m}$ when $t / T=20$ and 60 

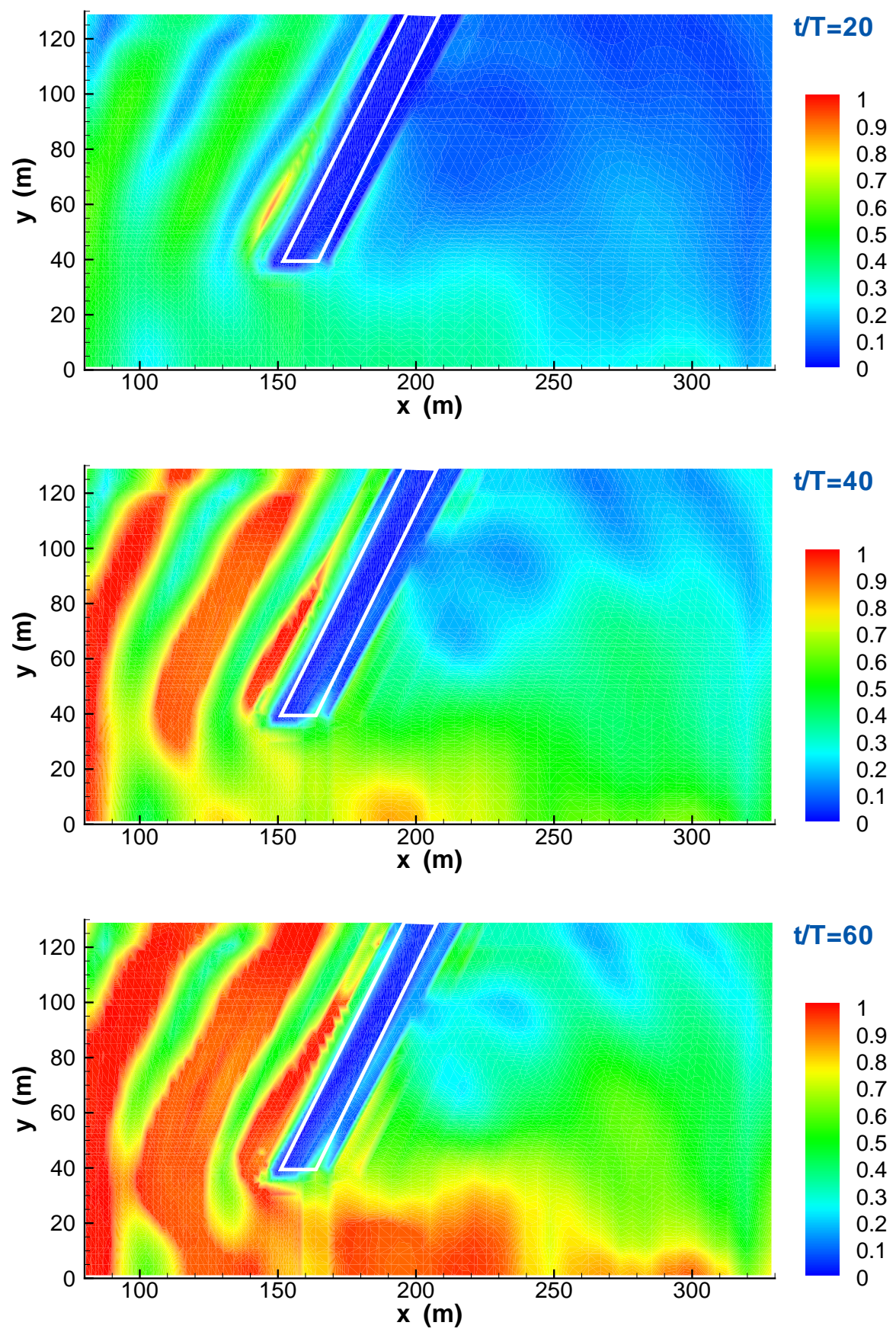

Figure 20: Distribution of liquefaction potential in the seabed foundation on $z=12.5 \mathrm{~m}$ when $t / T=20,40$ and 60 for the cases $\theta=60^{\circ}$ 

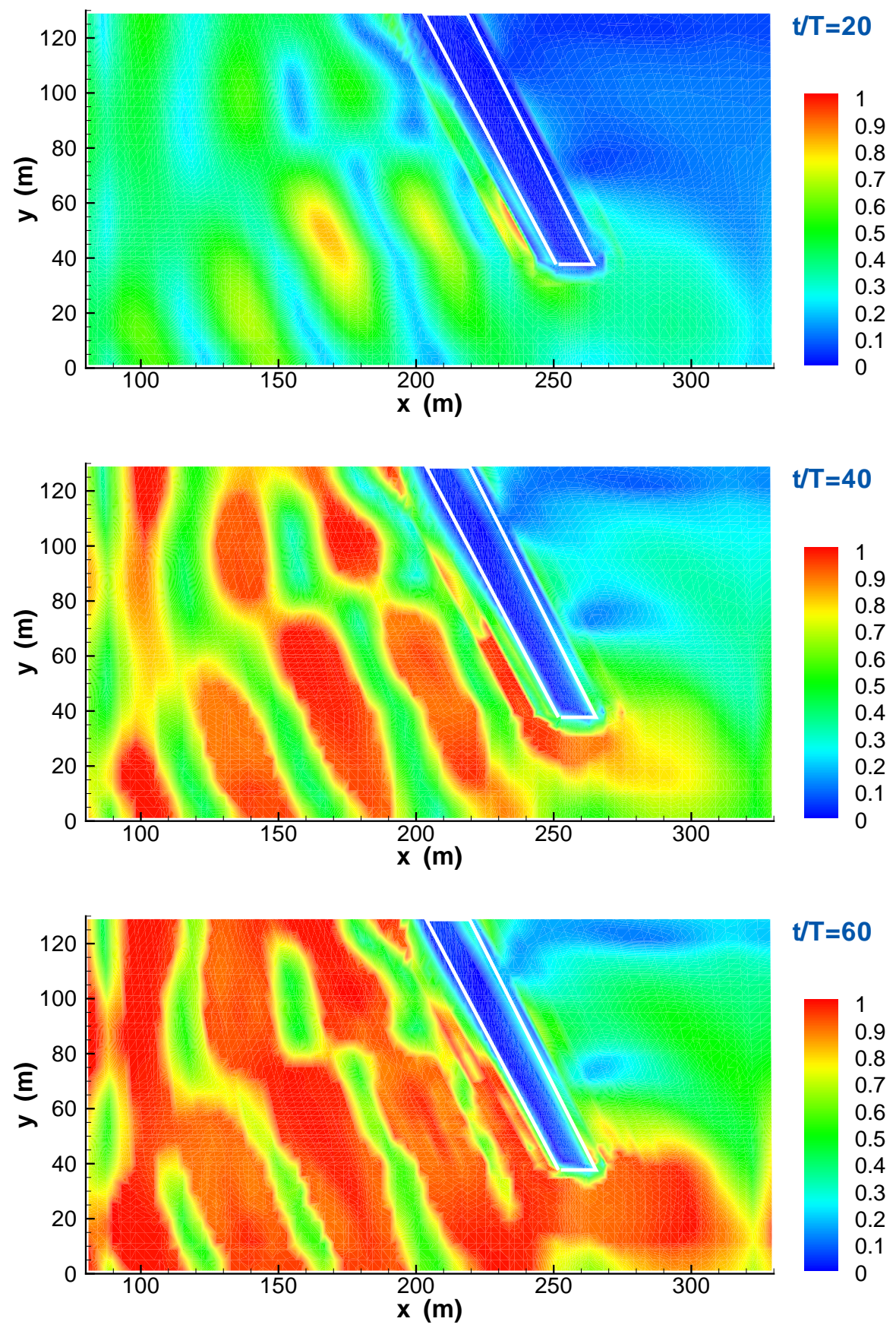

Figure 21: Distribution of liquefaction potential in the seabed foundation on $z=12.5 \mathrm{~m}$ when $t / T=20,40$ and 60 for the cases $\theta=120^{\circ}$ 
breakwater is much less than that in front of it at the same time. Also due to the compression of the caisson breakwater, residual liquefaction potential beneath the caisson breakwater is apparently small, nearly zero.

Comparing the distributions of residual liquefaction potential shown in Figure 19 with that shown in Figure 20 and 21, it is found that the direction of the caisson breakwater indeed has significant effect on the distribution of wave-induced residual liquefaction in the seabed foundation around the caisson breakwater. The zones with high and low residual liquefaction potential distribute alternately in the seabed foundation in front of the caisson breakwater; and they are basically parallel with the direction of the breakwater. In the zones with low residual liquefaction potential, $L_{\text {potential }}$ can reach up to $0.5-0.6$ when $\theta=60^{\circ}$ and $\theta=120^{\circ}$. However, $L_{\text {potential }}$ in these counterpart zones is nearly zero in the case $\theta=90^{\circ}$. Overall, $3 \mathrm{D}$ wave-induced residual liquefaction in the seabed foundation in front of the caisson breakwater is most intensive when $\theta=120^{\circ}$.

\section{Conclusions}

The interaction between 3D ocean wave, a caisson breakwater and its loosely deposited seabed foundation is investigated adopting an integrated numerical model FSS-CAS 3D. The interaction mechanism of wave, breakwater and loose seabed foundation is analyzed comprehensively through the presented numerical results. It is indicated that the interaction mechanism of FSSI problme involving loose seabed foundation is much more complicated than that only very dense (elastic) seabed foundation involved. It is also shown that the developed integrated numerial model FSSI-CAS 3D can effectively capture a series of nonlinear characteristics of FSSI problme. It would be a recommendable computational model for FSSI problme involving loose seabed foundation. The followings are some specific summries from the numerical analysis.

(1) Due to the soil compaction in loose seabed under cyclic wave loading, breakwater built on loose seabed foundation continuously subsides and tilts. The subsidence and tilting of breakwater mainly depend on the magnitude of wave impact, as well as the properties of loose seabed soil,

(2) Under wave loading, pore pressure in loose seabed foundation builds up; and effective stresses between soil particles decrease correspondingly. The rate of pore pressure build up in loose seabed foundation in front of breakwater is much greater than that behind breakwater; and rate of the pore pressure build up in loose seabed foundation is oppositely related to buried depth.

(3) Pore pressure in loose seabed foundation can not build up infinitely. There is a liquefaction resistance line to constrain the development of pore pressure. When wave-induced residual pore pressure at a position 
reaches liquefaction resistance line, it means that the excess residual pore pressure is sufficient to overcome liquefaction resistance, seabed soil at this position becomes liquefied. The analysis indicates that wave-induced residual liquefaction in front of a breakwater is a progressive process. The liquefaction depth moves downward in loose seabed foundation gradually under wave loading. Seabed foundation beneath breakwater is a unique zone. Pore pressure in this zone also builds up significantly. However, effective stresses between soil particles increase. This phenomenon is completely different from that in other zones around the breakwater. The reason for this phenomenon is that the wave-induced swaying and tilting of breakwater makes the soil particles in the seabed beneath breakwater rearrange themself in a denser way.

(4) Liquefaction analysis indicates that wave-induced residual liquefaction potential is much greater in front of breakwater than that behind breakwater; and their residual liquefaction potential increases with the time of wave loading. The zones with high and low residual liquefaction potential in loose seabed foundation in front of breakwater distribute alternately, and the pattern of the liquefaction zones are parallel with breakwater.

(5) Parametric study indicates that the direction of breakwater has significant effect on the distribution of wave-induced residual liquefaction in loose seabed foundation around breakwater head. This is attributed to that different wave fields are formed around the breakwater head.

\section{Acknowledgements}

Dr Ye Jianhong appreciates the finacial funding support from National Natural Science Foundation of China under project NO.41472291. Prof. Wang and Prof. Zhu thank the financial support from Chinese 973 Project: Evolutionary Trends and Sustainable Utilization of Coral Reefs in the South China Sea (2013CB956104). Dr Ye and Prof. Jeng are grateful for the financial support from EPSRC\#EP/G006482/1. Dr Ye also appreciates the funding support of Overseas Research Student Award from Scottish Government, UK.

\section{References}

Blom, F. J. (1998). A monolithical fluid-structure interaction algorithm applied to the piston problem. Computer methods in applied mechanics and engineering, 167(3):369-391.

Cheng, L., Sumer, B. M., and Fredsoe, J. (2001). Solution of pore pressure build up due to progressive waves. International Journal for Numerical and Analytical Method in Geomechanics, 25(9):885-907. 
Dunn, S. L., Vun, P. L., Chan, A. H. C., and Damgaard, J. S. (2006). Numerical modeling of wave-induced liquefaction around pipelines. Journal of Waterway, Port, Coastal and Ocean Engineering, 132(4):276-288.

Farhat, C. and Lesoinne, M. (2000). Two efficient staggered algorithms for the serial and parallel solution of three-dimensional nonlinear transient aeroelastic problems. Computer methods in applied mechanics and engineering, 182(3):499-515.

Groot, M. B. D., Kudella, M., Meijers, P., and Oumeraci, H. (2006). Liquefaction phenomena underneath marine gravity structures subjected to wave loads. Journal of Waterway, Port, Coastal and Ocean Engineering ASCE, 132(4):325-335.

Hsu, J. R. and Jeng, D. S. (1994). Wave-induced soil response in an unsaturated anisotropic seabed of finite thickness. International Journal for Numerical and Analytical Methods in Geomechanics, 18(11):785-807.

Hur, D. S., Kim, C. H., and Yoon, J. S. (2010). Numerical study on the interaction among a nonlinear wave, composite breakwater and sandy seabed. Coastal Engineering, 57(10):917-930.

Ishihara, K. (1993). Liquefaction and flow failure during earthquakes. Géotechnique, 43(3):351-451.

Kammerer, A. M., Pestana, J. M., and Seed, R. B. (2002). Undrained response of monterey 0/30 sand under multidirectional cyclic simple shear loading conditions. Technical report, University of California, Berkeley. Geotechnical Engineering Research Report No. UCB/GT/02-01.

Kirca, V. S. O., Summer, B. M., and Fredse, J. (2013). Residual liquefaction of seabed under standing waves. Journal of Waterway, Port, Coastal, and Ocean Engineering, 139(6):489-501.

Kudella, M., Oumeraci, H., Groot, M. B. D., , and Meijers, P. (2006). Liquefaction phenomena underneath marine gravity structures subjected to wave loads. Journal of Waterway, Port, Coastal and Ocean Engineering ASCE, 132(4):310-324.

Li, J. and Jeng, D. S. (2008). Response of a porous seabed around breakwater heads. Ocean Engineering, 35(8-9):864-886.

Lin, Z. P. and Liu, P. L.-F. (1999). Internal wave-maker for navier-stokes equations models. Journal of Waterway, Port, Coastal, and Ocean Engineering, 99(4):207-215.

Mizutani, N., Mostarfa, A., and Iwata, K. (1998). Nonliear regular wave, submerged breakwater and seabed dynamic interaction. Coastal Engineering, 33:177-202. 
Pastor, M., Chan, A. H. C., Mira, P., Manzanal, D., Fernndez, M. J. A., and Blanc, T. (2011). Computational geomechanics: The heritage of olek zienkiewicz. International Journal for Numerical Methods in Engineering, 87(1-5):457-489.

Pastor, M., Zienkiewicz, O. C., and Chan, A. H. C. (1990). Generalized plasticity and the modelling of soil behaviour. International Journal for Numerical and Analytical Methods in Geomechanics, 14:151-190.

Rahman, M. S. and Jaber, W. Y. (1986). Simplified drained analysis for wave-induced liquefaction in ocean floor sands. Soils and Foundations, 26(3):57-68.

Sassa, S. and Sekiguchi, H. (1999). Wave-induced liquefaction of beds of sand in a centrifuge. Géotechnique, 49(5):621-638.

Sassa, S. and Sekiguchi, H. (2001). Analysis of wave-induced liquefaction of sand beds. Géotechnique, 51(2):115-126.

Sassa, S., Sekiguchi, H., and Miyamoto, J. (2001). Analysis of progressive liquefaction as a moving-boundary problem. Géotechnique, 51(10):847-857.

Sumer, B. M., Kirca, V. S. O., and Fredsoe, J. (2011). Experimental validation of a mathematical model for seabed liquefaction in waves. In Proceedings of the International Offshore and Polar Engineering Conference, pages 1010-1018.

Teh, T. C., Palmer, A. C., and Damgaard, J. S. (2003). Experimental study of marine pipelines on unstable and liquefied seabed. Coastal Engineering, 50(1-2):1-17.

Tsai, C. P. (1995). Wave-induced liquefaction potential in a porous seabed in front of a breakwater. Ocean Engineering, 22(1):1-18.

Wu, J., Kammaerer, A. M., Riemer, M. F., Seed, R. B., and Pestana, J. M. (2004). Laboratory study of liquefaction triggering criteria. In Proceedings of 13th World Conference on Earthquake Engineering, Vancouver, British Columbia, Canada. Paper No. 2580.

Wu, J., Seed, R. B., and Pestana, J. M. (2003). Liquefaction triggering and post liquefaction deformations of monterey 0/30 sand under uni-directional cyclic simple shear loading. Technical report, University of California, Berkeley. Geotechnical Engineering Research Report No. UCB/GE-2003/01. 
Ye, J., Huang, D., and Wang, G. (2016a). Nonlinear dynamic simulation of offshore breakwater on sloping liquefied seabed. Bulletin of Engineering Geology and the Environment, 75(3):1215-1225.

Ye, J., Jeng, D., Wang, R., and Zhu, C. (2015). Numerical simulation of the wave-induced dynamic response of poro-elastoplastic seabed foundations and a composite breakwater. Applied Mathematical Modelling, 39:322-347.

Ye, J., Jeng, D. S., Chan, A. H. C., Wang, R., and Zhu, Q. (2016b). 3D integrated numerical model for fluidcstructurescseabed interaction (FSSI): Elastic dense seabed foundation. Ocean Engineering, 115:107122.

Ye, J. and Wang, G. (2016). Numerical simulation of the seismic liquefaction mechanism in an offshore loosely deposited seabed. Bulletin of Engineering Geology and the Environment, 75(3):1183-1197.

Ye, J. H. (2012). 3D liquefaction criteria for seabed considering the cohesion and friction of soil. Applied Ocean Research, 37:111-119.

Ye, J. H., Jeng, D.-S., and Chan, A. H. C. (2012). Consolidation and dynamics of 3D unsaturated porous seabed under rigid caisson breakwater loaded by hydrostatic pressure and wave. Science China-Technological Sciences, 55(8):2362-2376.

Ye, J. H., Jeng, D.-S., Wang, R., and Zhu, C. Q. (2013a). A 3-D semi-coupled numerical model for fluidstructuresseabed-interaction (FSSI-CAS 3D): Model and verification. Journal of Fluids and Structures, 40:148-162.

Ye, J. H., Jeng, D.-S., Wang, R., and Zhu, C. Q. (2013b). Validation of a 2D semi-coupled numerical model for Fluid-Structures-Seabed Interaction. Journal of Fluids and Structures, 42:333-357.

Ye, J. H. and Wang, G. (2015). Seismic dynamics of offshore breakwater on liquefiable seabed foundation. Soil Dynamics and Earthquake Engineering, 76:86-99.

Zhang, X. Y., Lee, F. H., and Leung, C. F. (2009). Response of caisson breakwater subjected to repeated impulsive loading. Géotechnique, 59(1):3-16.

Zienkiewicz, O. C., Chan, A. H. C., Pastor, M., Schrefler, B. A., and Shiomi, T. (1999). Computational Geomechanics with Special Reference to Earthquake Engineering. John Wiley and Sons, England. 